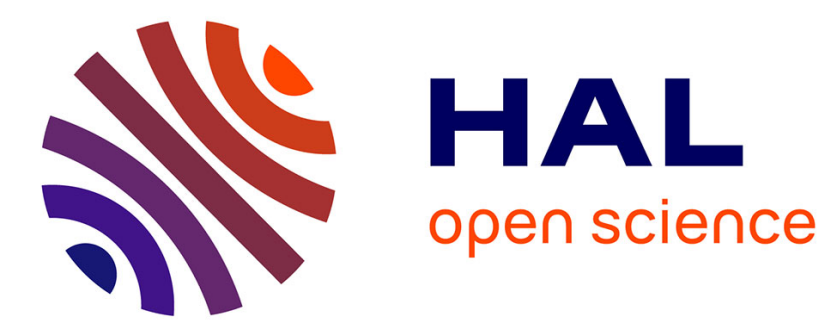

\title{
Influence de la translucidité de l'emballage sur la conservation du lait et des produits laitiers
}

Jo Bosset, Pu Gallmann, R Sieber

\section{To cite this version:}

Jo Bosset, Pu Gallmann, R Sieber. Influence de la translucidité de l'emballage sur la conservation du lait et des produits laitiers. Le Lait, 1993, 73 (1), pp.3-49. hal-00929315

\section{HAL Id: hal-00929315 https://hal.science/hal-00929315}

Submitted on 1 Jan 1993

HAL is a multi-disciplinary open access archive for the deposit and dissemination of scientific research documents, whether they are published or not. The documents may come from teaching and research institutions in France or abroad, or from public or private research centers.
L'archive ouverte pluridisciplinaire HAL, est destinée au dépôt et à la diffusion de documents scientifiques de niveau recherche, publiés ou non, émanant des établissements d'enseignement et de recherche français ou étrangers, des laboratoires publics ou privés. 


\title{
Article de synthèse
}

\section{Influence de la translucidité de l'emballage sur la conservation du lait et des produits laitiers *}

\author{
JO Bosset, PU Gallmann, R Sieber \\ Station fédérale de recherches laitières, $\mathrm{CH}-3097$ Liebefeld-Beme, Suisse
}

(Reçu le 6 novembre 1992; accepté le 13 novembre 1992)

\begin{abstract}
Résumé - Le présent travail opère une synthèse des connaissances et des résultats acquis par les auteurs et leurs collègues au cours des 10 dernières années lors d'une série d'essais consacrés à l'étude de la photosensibilité du lait et des produits laitiers, du yoghourt et du beurre en particulier. II complète cette synthèse par une vaste revue bibliographique des publications qui ont paru sur ce sujet jusqu'à aujourd'hui. Deux aspects importants y sont particulièrement traités : les principaux facteurs extrinsèques et intrinsèques qui influencent la photodégradation ainsi que les effets proprement dits de la lumière sur quelques constituants chimiques et grandeurs chimico-physiques du lait et des produits laitiers. Parmi les principaux facteurs extrinsèques qui peuvent diminuer ou accroitre la photo-oxydation, on peut citer le spectre, l'intensité et la durée de la lumière incidente, la translucidité de l'emballage et sa perméabilité à l'oxygène, de même que la température du stockage. Le choix de ces facteurs doit chaque fois être opéré en fonction des facteurs intrinsèques qui déterminent la photosensibilité du produit considéré. Au nombre de ces facteurs, on peut mentionner la composition globale (en particulier la teneur en substances oxydantes et réductrices), la valeur du $\mathrm{pH}$, le potentiel d'oxydo-réduction ainsi que le traitement technologique du produit. Les principaux effets de la lumière sur le lait et les produits laitiers sont les suivants : pertes en vitamines, en particulier en riboflavine (qui agit comme photosensibilisateur), en $\beta$-carotène et en acide ascorbique, production ou dégradation d'acides aminés libres, augmentation de l'indice de peroxydes, altération de la flaveur avec l'apparition de composés désagréables (méthional provenant de la dégradation des protéines, aldéhydes et méthylcétones provenant de celle des lipides) et modification de la couleur du produit photolysé. Ce travail compare encore les cinétiques d'altération et les seuils de détection des composés impliqués dans les réactions de photodécomposition. Ce travail s'achève par quelques recommandations pratiques générales.
\end{abstract}

lait / produits laitiers / lumière / photo-oxydation / photodégradation / emballage

Summary - Influence of light transmittance of packing materials on the shelf-life of milk and dairy products - a review. This paper resumes the test results obtained by the authors and their

\footnotetext{
* Extension d'une communication présentée sous la forme d'une conférence lors du séminaire FIL IDF «Protein and fat globule modifications by heat treatment, homogenization and other technological means for high quality dairy products" à Munich, 25-28 août 1992 (PU Gallmann) et d'une conférence principale prononcée lors du colloque "Conditionnement alimentaire - 2 défis : Innovation et environnement", 7 et 8 octobre 1992 à Pouzauges, France (JO Bosset)
} 
colleagues during the last $10 \mathrm{yr}$ on photodegradation of milk and dairy products, particularly yoghurt and butter. The review is completed by numerous data from the relevant literature. Two major aspects are highlighted: the external and inherent factors that influence photooxidation and the effects of light on some chemical components or physico-chemical parameters of milk and dairy products. The principal external factors that influence photooxidation are: the spectrum and intensity of the light source, the conditions of light exposure (geometry, duration etc), the light transmittance and the oxygen permeability of the packaging material as well as the storage temperature. These factors must be selected as a function of the inherent factors responsible for the photosensitivity of the product. The latter include the composition (particularly oxidant and antioxidant contents), $\mathrm{pH}$, redox potential and processing of the product. Light induces loss of vitamins, especially riboflavin (which also acts as a photosensitizer), $\beta$-carotene and vitamin $C$, production or degradation of free amino acids, increase of the peroxide value, formation of sensorially unpleasant volatile compounds (methional, aldehydes and methyl ketones) as well as colour changes. The kinetics of these alterations and the limits of detection of the involved compounds are compared. Some practical recommendations complete this study.

milk / dairy products / light / photooxidation / photodegradation / packaging

\section{INTRODUCTION}

Dans bien des cas, les denrées alimentaires ne sont pas destinées à être consommées immédiatement après leur production. Elles sont souvent retravaillées jusqu'à l'obtention du "produit fini», puis stockées et transportées, souvent sur de longues distances jusqu'au consommateur. À l'aide d'un emballage adéquat, on tente donc d'en prévenir toute dégradation de nature chimique, biochimique, chimicophysique, microbiologique ou mécanique (fig 1). Outre ses fonctions protectrices, l'emballage sert également de contenant pour le produit, ainsi que de support pour la désignation et la description du contenu, voire pour sa promotion. Parmi toutes ces fonctions, celle de protection contre la lumière joue un rôle clé, en particulier pendant le stockage, le transport et la mise en vente des denrées alimentaires. $\grave{A}$ cette fin, plusieurs sortes d'emballages sont actuellement disponibles - à des coûts et avec des propriétés très divers -, allant de la simple feuille de carton ou de papier parcheminé à la luxueuse boîte métallique, en passant par toutes les feuilles de plastique et d'aluminium, sans omettre les emballages de verre, généralement recyclables.

Les produits alimentaires et les boissons présentent des sensibilités très variables à la lumière naturelle ou artificielle (Bekbölet, 1990). En raison de leur composition, le lait et les produits laitiers constituent d'ailleurs un cas idéal pour effectuer de telles études (Stull, 1953; Sattar et deMan, 1975; Bradley, 1980; Dimick, 1982; Bojkow, 1984; Janda, 1990). La photosensibilité dépend surtout de leur composition globale et de leur teneur en riboflavine en particulier, qui agit comme photosensibilisateur. Maints autres composés tels que produits soufrés, antioxydants et métaux lourds, ainsi que la composition de la matière grasse jouent en général un rôle déterminant. La photosensibilité des produits alimentaires dépend encore de nombreux autres facteurs, au nombre desquels on peut citer :

- leur teneur en oxygène dissous ou disponible, donc la perméabilité de leur emballage à ce gaz;

- leur température;

- la durée de leur exposition à la lumière ainsi que l'intensité et le spectre d'émission de la source utilisée; 


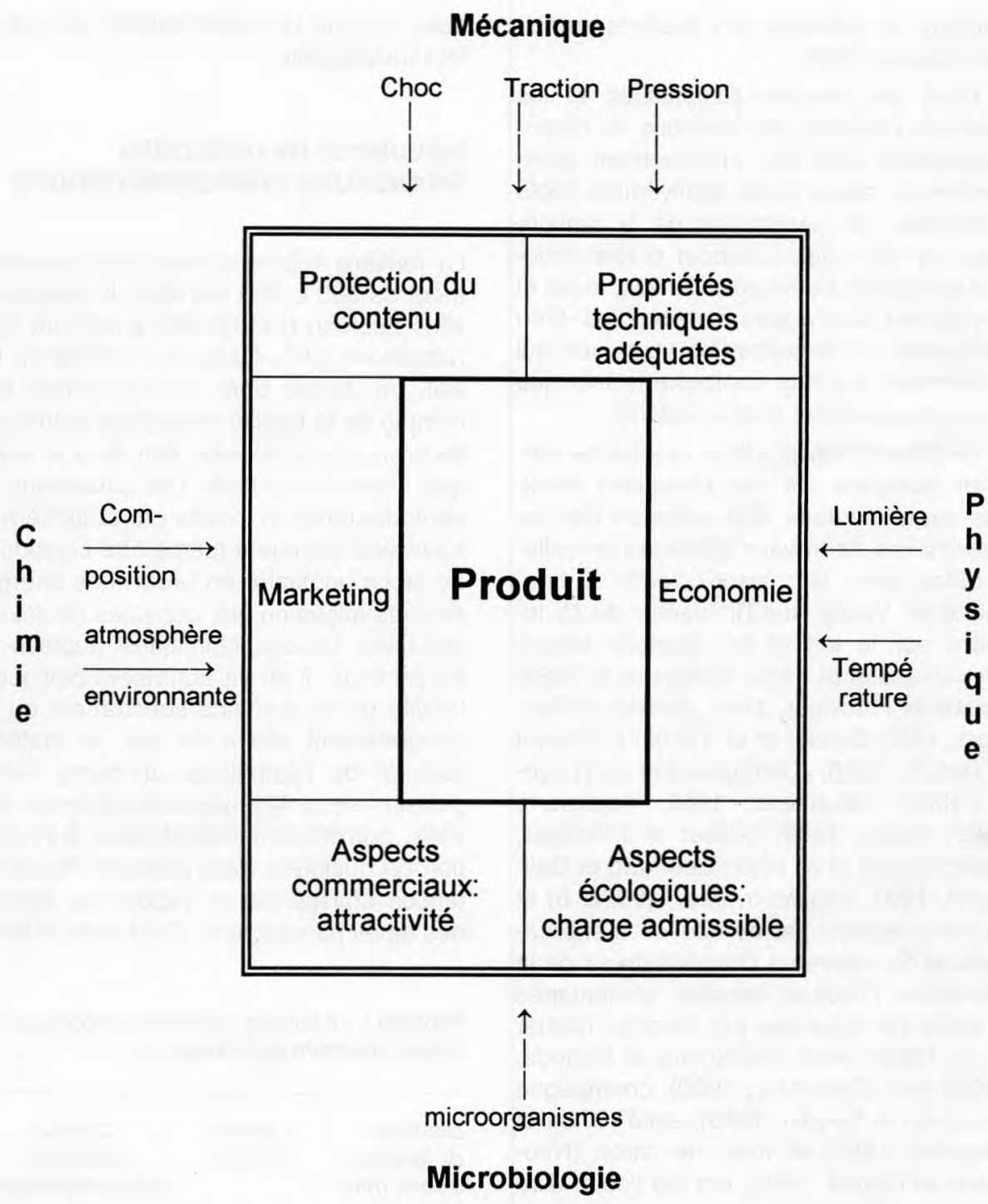

Fig 1. Interdépendance du couple contenant (emballage) et contenu : profils des exigences posées et des influences subies.

Interdependence of package and product: influences and requirements.

- la translucidité de leur emballage, qui détermine le niveau énergétique des réactions de photo-oxydation;

- leurs caractéristiques spectrales de réflexion, de transmission et d'absorption.
Le risque d'apparition de défauts dus à la lumière est encore accru par certains facteurs tels que l'influence de la saison (plus grande sensibilité en hiver), l'homogénéisation du lait, de même que la tem- 
pérature de stockage des produits emballés (Bojkow, 1970).

Dans les denrées alimentaires et les boissons opaques, les réactions de photodégradation n'ont lieu pratiquement qu'en surface en raison de la relativement faible profondeur de pénétration de la lumière dans de tels milieux, surtout si leur structure est solide. De ce point de vue, le lait et le yoghourt nature sont comparables. S'en distinguent en revanche les yoghourts qui contiennent d'autres composants tels que pigments, colorants et antioxydants.

Le présent travail a pour objectif de rappeler quelques-uns des principaux résultats expérimentaux déjà obtenus par les auteurs lors de travaux effectués en collaboration avec la maison Nestlé à Lausanne et Vevey sur l'influence de la lumière sur le lait et les produits laitiers (Desarzens et al, 1983; Bosset et al, 1983; Bosset et Flückiger, 1985; Bosset et Flückiger, 1986; Bosset et al, 1986a, b; Bosset et Gauch, 1988; Dieffenbacher et Trisconi, 1988; Desarzens, 1988; Tagliaferri, 1989; Daget, 1989; Bosset et Flückiger, 1989; Bosset et al, 1991; Eberhard et Gallmann, 1991; Tagliaferri et al, 1992a, b) et de les compléter par de nouvelles explications et de nouvelles données tirées de la littérature. D'autres denrées alimentaires et boissons telles que jus d'orange (Sattar et al, 1989), bière (Kamimura et Kaneda, 1992), thé (Chen et al, 1992), champagne (Maujean et Seguin, 1983), saké (Ohba et Akiyama, 1992) et huile de citron (Neumann et Garcia, 1992) ont fait l'objet d'investigations analogues.

En dépit de leur importance grandissante pour une société dite de consommation, les aspects technologiques, économiques et écologiques des divers matériaux actuellement utilisés ne seront pas traités dans le cadre de ce travail. On devra néanmoins en tenir compte impérativement pour le choix définitif des emballages, à côté d'aspects purement techni- ques comme leur perméabilité aux gaz et leur translucidité.

\section{INFLUENCE DE QUELQUES GRANDEURS CHIMICO-PHYSIQUES}

La lumière solaire s'étend approximativement de 380 à $750 \mathrm{~nm}$ dans le spectre visible (tableau I) et de 200 à $380 \mathrm{~nm}$ dans l'ultraviolet (UV). Dans le cadre de ce travail, on devrait donc théoriquement tenir compte de la totalité du spectre d'émission de la source lumineuse, tant dans le visible que dans l'ultraviolet. Les processus de photodégradation induits par la lumière ultraviolette devraient même être considérés de façon prioritaire en raison des énergies élevées mises en jeu, capables de scinder certaines liaisons chimiques (tableau II). En pratique, il en va autrement puisque la totalité de ce domaine spectral est en fait intégralement absorbée par le matériau (cut-off) de l'emballage lui-même (verre, polystyrène, polyéthylène de diverses densités, polyéthylènetéréphtalate), à l'exception de quelques raies particulièrement intenses émises par la vapeur de mercure des tubes fluorescents. C'est donc le début

Tableau I. Le spectre visible et ses couleurs. Visible spectrum and its colours.

\begin{tabular}{lll}
\hline $\begin{array}{l}\text { Domaine } \\
\text { de longueur } \\
\text { d'onde }(\mathrm{nm})\end{array}$ & $\begin{array}{l}\text { Couleur } \\
\text { perçue }\end{array}$ & $\begin{array}{c}\text { Couleur } \\
\text { absorbée } \\
\text { (complémentaire) }\end{array}$ \\
\hline $380-440$ & Violet & $\begin{array}{l}\text { Jaune-vert } \\
\text { Jaune }\end{array}$ \\
$440-480$ & Bleu & Orange \\
$480-490$ & Vert-bleu & Rouge \\
$490-500$ & Bleu-vert & Pourpre \\
$500-560$ & Vert & Pour \\
$560-580$ & Jaune-vert & Violet \\
$580-600$ & Jaune & Bleu \\
$600-620$ & Orange & Vert-bleu \\
$620-750$ & Rouge & Bleu-vert \\
\hline
\end{tabular}


Tableau II. Énergie de quelques liaisons chimiques et longueurs d'onde correspondantes (Sattar et de Man, 1975).

Energy level of some chemical bonds and corresponding wavelengths.

\begin{tabular}{|c|c|}
\hline $\begin{array}{l}\text { Liaisons chimiques dans les molécules } \\
(\mathrm{kcal} / \mathrm{mol})\end{array}$ & $\begin{array}{l}\text { Longueur d'onde } \\
(\mathrm{nm})\end{array}$ \\
\hline
\end{tabular}

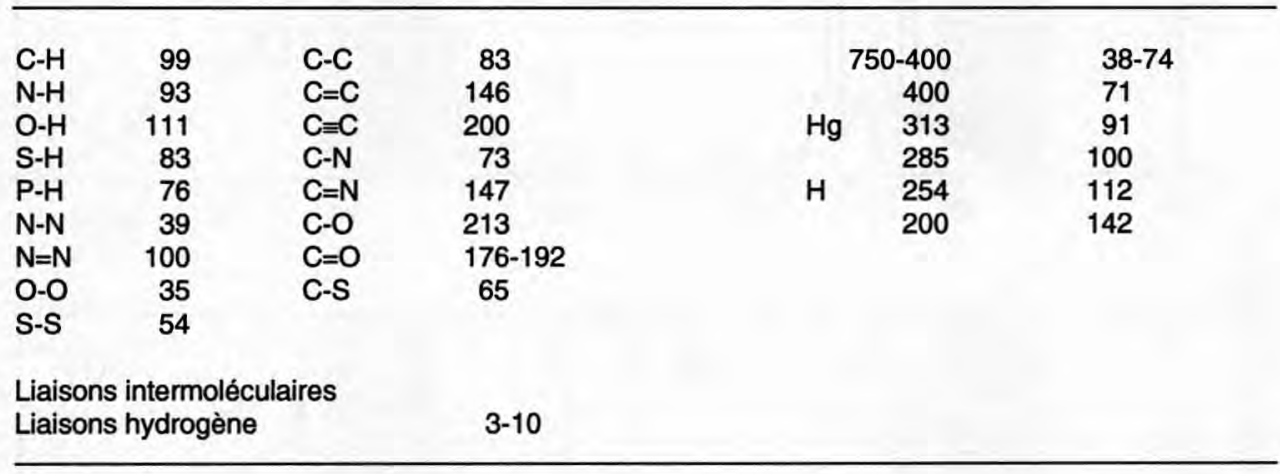

du spectre d'émission dans le visible (de 420 à $520 \mathrm{~nm}$ environ) qui peut poser problème, surtout en présence de riboflavine (cf zones ombrées des figures 2 à 6 ).

\section{Spectre d'émission du soleil}

Le spectre d'émission de la lumière dite du jour ou naturelle (fig 2) est très vaste, homogène et riche en hautes énergies, tant dans le visible que dans l'ultraviolet. En ce qui concerne la photodégradation du lait et des produits laitiers, toute exposition directe au soleil, même de quelques minutes, doit être évitée. La situation est en revanche beaucoup moins critique en présence de tubes fluorescents (lumière dite artificielle), moins riches en énergie.

\section{Spectre d'émission des tubes fluorescents}

La figure 3 montre les spectres d'émission de quelques tubes fluorescents usuels du commerce. Le tableau III en rappelle quel-

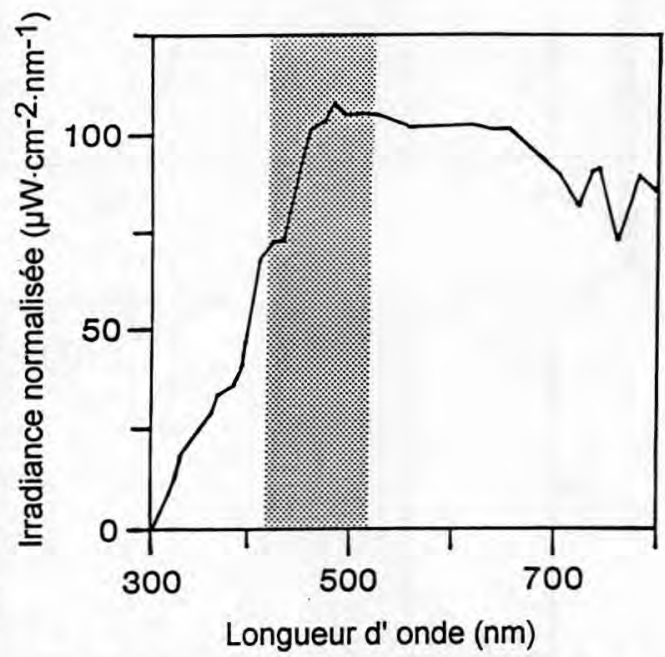

Fig 2. Spectre d'émission de la lumière solaire, dite naturelle (anonyme).

Emission spectrum of sunlight.

ques caractéristiques importantes ainsi qu'une liste des utilisations possibles. Les tubes fluorescents émettant une lumière polychromatique (blanche) peuvent être groupés en 2 grandes classes : 

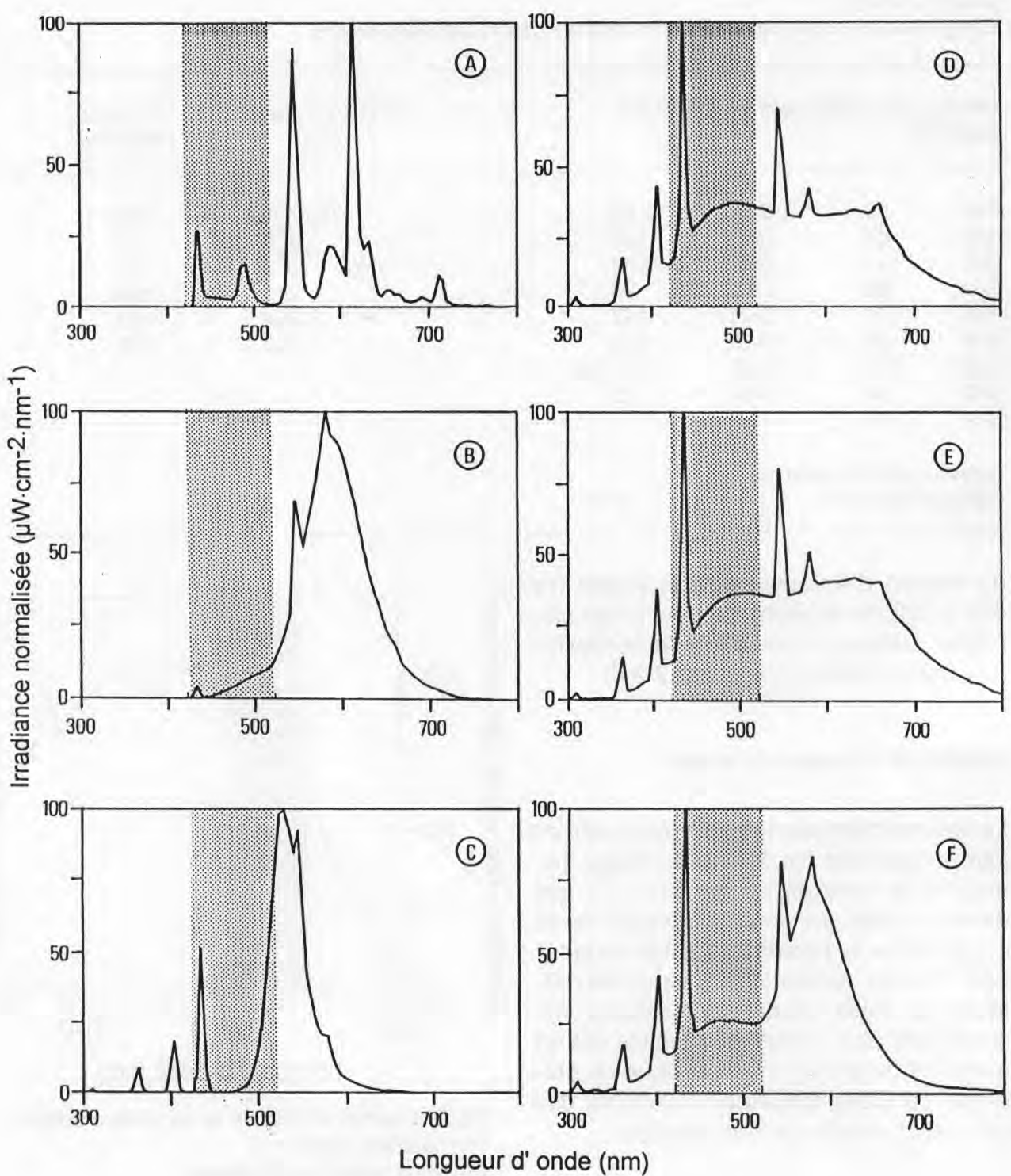

Fig 3. Spectres d'émission de divers tubes fluorescents du commerce (Bosset et al, 1983). A) Philips $83 / 36$ W blanc; B) Philips 16/40 W jaune; C) Philips $17 / 40$ W vert; D) Philips 55/40 W lumière de jour; E) Osram 19/40 W lumière de jour; F) Philips $33 / 40 \mathrm{~W}$ blanc.

Emission spectra of some commercial fluorescent tubes. A) Philips $83 / 36 \mathrm{~W}$ white; B) Philips 16/40 W yellow; C) Philips 17/40 W green; D) Philips 55/40 W daylight; E) Osram 19/40 W daylight; F) Philips 33/40 W white. 
Tableau III. Caractéristiques et spécifications des tubes fluorescents utilisés (Bosset et al, 1983).

Technical data (characteristics and specifications) of commercial fluorescent tubes (Bosset et al, 1983).

\begin{tabular}{|c|c|c|c|c|c|c|c|c|c|c|}
\hline & $\begin{array}{l}\text { Marque } \\
\text { type et } \\
\text { puissance }\end{array}$ & $\begin{array}{c}\text { Irradian } \\
(\mu W \\
400- \\
500 \mathrm{~nm}\end{array}$ & $\begin{array}{l}\text { e intégrée } \\
\left(\mathrm{cm}^{2}\right)^{*} \\
380- \\
700 \mathrm{~nm}\end{array}$ & $\begin{array}{l}\text { Température } \\
\text { de couleur } \\
\text { (K) }\end{array}$ & $\begin{array}{l}\text { Flux } \\
\text { (Im) }\end{array}$ & $\begin{array}{l}\text { Désignation } \\
\text { couleur }\end{array}$ & $\begin{array}{l}\text { Rendu des } \\
\text { couleurs }\end{array}$ & $\begin{array}{l}\text { Rendement } \\
\text { lumineux }\end{array}$ & Destination/application & $\begin{array}{l}\text { Equivalent } \\
\text { commercial }\end{array}$ \\
\hline A & $\begin{array}{l}\text { Philips } \\
83 / 36 \mathrm{~W}\end{array}$ & 370 & 2630 & 3000 & 3400 & $\begin{array}{l}\text { Blanc chaud } \\
\text { de luxe }\end{array}$ & Très bon & Très bon & $\begin{array}{l}\text { Bureaux, locaux de vente, } \\
\text { restaurants et habitations }\end{array}$ & Osram 31 \\
\hline B & $\begin{array}{l}\text { Philips } \\
\text { 16/40 W }\end{array}$ & 190 & 6220 & - & 2000 & Jaune & - & - & Décorations & - \\
\hline c & $\begin{array}{l}\text { Philips } \\
17 / 40 \mathrm{~W}\end{array}$ & 470 & 4120 & - & 3300 & Vert & - & - & Décorations & - \\
\hline - & $\begin{array}{l}\text { Philips } \\
18 / 40 \text { W }\end{array}$ & ** & ** & - & 650 & Bleu & - & - & Décorations & - \\
\hline D & $\begin{array}{l}\text { Philips } \\
55 / 40 \text { W }\end{array}$ & 2200 & 7300 & 6500 & 2020 & $\begin{array}{l}\text { Lumière du } \\
\text { jour }\end{array}$ & Bon & Bon & Éclairage vitrines & Osram 10 \\
\hline$E$ & $\begin{array}{l}\text { Osram } \\
19 / 40 \mathrm{~W}\end{array}$ & 2120 & 8200 & 5000 & 1900 & $\begin{array}{l}\text { Lumière du } \\
\text { jour de luxe }\end{array}$ & & & $\begin{array}{l}\text { Salles de conférence, } \\
\text { échantillonnage couleurs, } \\
\text { déconseillé pour alimentation }\end{array}$ & Philips 47 \\
\hline $\mathrm{F}$ & $\begin{array}{l}\text { Philips } \\
33 / 40 \text { W }\end{array}$ & 1950 & 7830 & 4200 & 3200 & Blanc & Bon & Bon & $\begin{array}{l}\text { Bureaux, industrie, éclairage } \\
\text { externe, magasins et entrepôts }\end{array}$ & Osram 20 \\
\hline - & $\begin{array}{l}\text { Philips } \\
\text { 29/40 W }\end{array}$ & $* *$ & $* *$ & 3000 & 3100 & Blanc chaud & Faible & Élevé & $\begin{array}{l}\text { Éclairage extérieur, } \\
\text { industrie lourde }\end{array}$ & Osram 30 \\
\hline- & $\begin{array}{l}\text { Philips } \\
\text { 82/36 W }\end{array}$ & $\star \star \star$ & ** & 25509 & 3250 & $\begin{array}{l}\text { Blanc chaud } \\
\text { extra }\end{array}$ & - & - & Appartements & - \\
\hline- & $\begin{array}{l}\text { Thorn } \\
\text { NX/4OW }\end{array}$ & ** & ** & 3600 & 1750 & $\begin{array}{l}\text { Lumière du } \\
\text { jour naturelle }\end{array}$ & Bon & - & $\begin{array}{l}\text { Vente fleurs, viande, } \\
\text { fruits et légumes }\end{array}$ & Osram 36 \\
\hline - & $\begin{array}{l}\text { Thorn } \\
\text { KR/40 W }\end{array}$ & $* *$ & $\star \star \star$ & 4000 & 2000 & $\begin{array}{l}\text { Lumière du } \\
\text { jour }\end{array}$ & Excellent & - & - & \\
\hline - & $\begin{array}{l}\text { Thorn } \\
\text { TD/40W }\end{array}$ & $\star *$ & ** & 6500 & 2410 & $\begin{array}{l}\text { Lumière du } \\
\text { jour tropicale }\end{array}$ & - & - & - & Osram 10 \\
\hline
\end{tabular}

* Arrondie à la dizaine; ${ }^{\star \star}$ n'a pu être mesurée, le spectromètre prêté n'étant plus à disposition.

* Rounded off to $10 ;{ }^{* *}$ could not be measured, due to non availability of spectrometer. 
- ceux dits d'un blanc "froid", relativement riches en toutes les composantes colorées du visible;

- ceux dits d'un blanc "chaud", riches en composantes jaune, orange et rouge, mais assez pauvres en composantes violette, bleue et verte, donc moins riches en énergie.

En raison même de leur spectre d'émission assez riche en énergie, l'utilisation des tubes fluorescents d'un blanc "froid" est donc déconseillée pour l'éclairage des entrepôts, des vitrines et des présentoirs de denrées alimentaires photosensibles comme le lait et les produits laitiers. Cette restriction dans l'emploi de ces tubes fluorescents est consécutive à leur forte émission dans le bleu-vert (soit aux environs de $444 \mathrm{~nm}$ ) où se situe la troisième bande d'absorption de la riboflavine. Les tubes fluorescents tels que le Philips 33 présentent en outre plusieurs raies d'émission de leur vapeur de mercure à 366, 405 et $436 \mathrm{~nm}$ qui coïncident également avec cette bande d'absorption de la riboflavine (Tagliaferri, 1989). Cette dernière fera d'ailleurs l'objet d'une discussion plus détaillée (cf Spectre d'absorption de la riboflavine).

\section{Éclairement usuel de présentoirs destinés aux laits et aux produits laitiers}

À côté des caractéristiques spectrales d'émission des tubes fluorescents utilisés, il faut également tenir compte de l'intensité globale de l'éclairage appliqué. Un éclairement de l'ordre de $2000 \mathrm{~lx}$ - valeur utilisée par la suite par les auteurs pour leurs propres essais - a été mesuré par les auteurs dans divers présentoirs destinés à la vente de laits et de produits laitiers (valeur non publiée). Cette valeur correspond d'ailleurs à ce que l'on trouve dans la littérature (Dimick, 1982). Dimick indique par exemple un éclairement moyen de $2000 \mathrm{~lx}$ pour les présentoirs de 105 libres services où $58 \%$ de la marchandise n'avait pas encore été vendue. Dans 3 autres études, l'éclairement variait de 269 à 5380 lx (Sattar et deMan, 1973), ou de 110 à 4950 Ix pour un autre groupe de 19 magasins (deMan, 1978) ou encore de 129 à 4303 Ix (Olsen et Ashoor, 1987).

\section{Trans/ucidité de l'emballage}

Le choix de l'emballage doit obéir aux mêmes règles que celui de la source de lumière. Toujours en raison de la troisième bande d'absorption de la riboflavine, on veillera aussi à éviter autant que possible les emballages laissant passer les bandes bleu-vert au profit d'emballages teintés ou pigmentés en brun-rouge, si toutefois une certaine translucidité est souhaitée pour rendre le produit plus attractif. Le tableau IV rapporte quelques valeurs de transmission de la lumière artificielle pour divers emballages destinés au lait. La figure 4 montre les spectres de transmission de 5 matériaux d'emballage récemment testés en Suisse pour le lait pasteurisé. Quatre d'entre eux sont constitués de feuilles de plastique dont 2 sont encore pourvus d'une barrière (brune ou noire) contre la lumière. Le cinquième emballage est constitué d'une feuille de carton plastifiée sans doublage d'aluminium (Aucun de ces matériaux ne peut être utilisé pour des laits UHT en raison de leur trop grande perméabilité à l'oxygène). La figure 5 indique les spectres de transmission de 5 autres matériaux d'emballage pour les yoghourts (pots de $180 \mathrm{~g}$ ), soit du verre incolore, du verre teinté brun-rouge, du polystyrène incolore, du polystyrène teinté brun-rouge et du polystyrène cartonné (type «k3»). 
Tableau IV. Translucidité de divers matériaux d'emballage du lait à la lumière fluorescente (Dimick, 1982).

Fluorescent light transmittance of milk packaging materials.

\begin{tabular}{lcc} 
Matériau d'emballage & Épaisseur $(\mathrm{mm})$ & Transmission (\%) \\
\hline Verre au plomb clair & 3,4 & 91 \\
Polycarbonate clair & 1,5 & 90 \\
Polycarbonate coloré & 1,5 & 75 \\
Polyéthylène non recyclable & 0,5 & 70 \\
Polyéthylène de haute densité & 1,7 & 57 \\
Matériau fibreux sans impression & 0,7 & 4
\end{tabular}

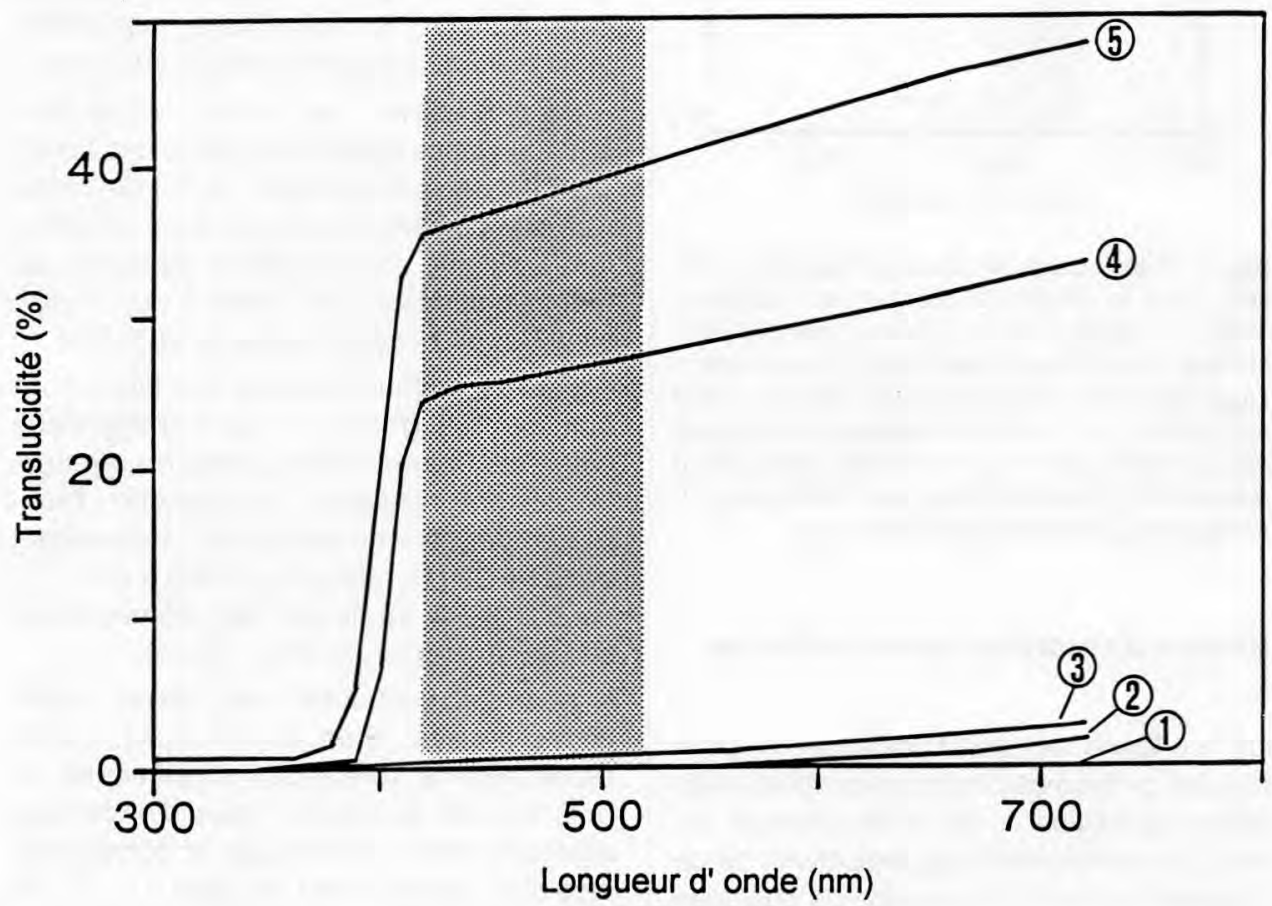

Fig 4. Translucidité de divers matériaux d'emballage du lait à la lumière fluorescente (Tagliaferri et al, 1992b). 1) Feuille plastique (avec film photoprotecteur noir); 2) feuille cartonnée (sans feuille d'aluminium); 3 ) feuille plastique (avec film photoprotecteur brun); 4) et 5) feuilles plastiques (sans film photoprotecteur).

Light transmittance of packaging materials used for pasteurised milk (bags). 1) Plastic with light barrier (black); 2) cardboard without aluminium foil; 3) plastic with light barrier (brown); 4) and 5) plastic without additional light barrier (spectra measured by EMPA, Dübendorf, on behalf on ToniMIBA Produktion AG, Zurich, with the kind permission of this company). 


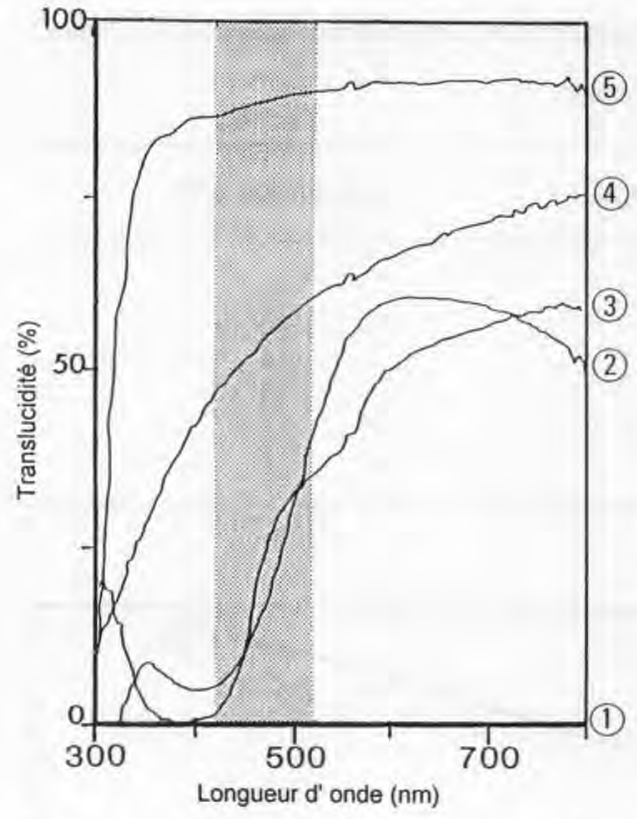

Fig 5. Translucidité de divers emballages utilisés pour le yoghourt (Bosset et Flückiger, 1986). 1) Carton ( « 33 ); 2) verre brun; 3) polystyrène brun; 4) polystyrène clair; 5) verre clair. Light transmittance of packaging materials used for yoghurt. 1) Cardboard wrapped polystyrene cup; 2) transparent brown-coloured glass jar; 3) transparent brown-coloured polystyrene cup; 4) transparent non-tinted polystyrene cup.

\section{Spectre d'absorption de la riboflavine}

La riboflavine est une substance clé pour tous les problèmes de photosensibilité et de photodégradation du lait et des produits laitiers. En complément aux indications de ce chapitre consacré à linfluence de quelques grandeurs chimico-physiques intervenant dans la photodégradation des produits laitiers, la figure 6 présente encore le spectre d'absorption de la riboflavine. Cette vitamine possède plusieurs bandes d'absorption dont les maxima sont situés vers 223 et $268 \mathrm{~nm}$ dans I'UV ainsi que vers $359-375$, 446 et $475 \mathrm{~nm}$ dans le visible. Dans les bande d'absorption les plus critiques, comprises entre 350 à $520 \mathrm{~nm}$ approximativement, ce sont surtout les longueurs d'onde situées entre 415 et $455 \mathrm{~nm}$ qui sont responsables de l'altération de la riboflavine (Sattar et al, 1977) et de l'apparition du défaut de goût dit "de lumière" (Bekbölet, 1990).

\section{RAPPEL DES PRINCIPALES CONDITIONS DE TRAVAIL ADOPTÉES PRÉCÉDEMMENT PAR LES AUTEURS}

Lors de diverses études effectuées sur ce thème par les auteurs et leurs collègues (on s'y référera pour y trouver un descriptif plus détaillé), les conditions expérimentales étaient sommairement les suivantes :

- pour divers laits et produits laitiers (soit $500 \mathrm{ml}$ ) placés directement dans des boîtes de Petri de verre incolore, de 1 I de contenance : éclairement pendant $6 \mathrm{~h}$ à température ambiante sous $20000 \mathrm{~lx}$ au moyen de tubes fluorescents d'un blanc froid, Philips type TL33/40 W (Desarzens et al, 1983);

- pour le yoghourt nature conditionné en pots de $180 \mathrm{~g}$ dans 5 types d'emballage différents (verre incolore, verre brun-rouge, polystyrène incolore, polystyrène brunrouge, polystyrène cartonné) : éclairement pendant $22 \mathrm{j}$ (à raison de $12 \mathrm{~h} / \mathrm{j}$ ) à env $8^{\circ} \mathrm{C}$ sous $2000 \mathrm{Ix}$ au moyen des mêmes tubes fluorescents (Bosset et al, 1986a);

- pour les yoghourts avec divers ingrédients (fraises, chocolat et mocca, nature repris comme référence) conditionnés en pots de $180 \mathrm{~g}$ dans 2 types d'emballage différents (verre brun-rouge et polystyrène incolore) : éclairement pendant $21 \mathrm{j}$ (à raison de $12 \mathrm{~h} / \mathrm{j}$ ) à env. $7{ }^{\circ} \mathrm{C}$ sous $2000 \mathrm{Ix}$ au moyen des mêmes tubes fluorescents (Bosset et Flückiger, 1989);

- pour un lait entier pasteurisé conditionné dans des sachets souples, en plastique blanc clair, faiblement translucide (car dépourvu de barrière à la lumière) : éclairement pendant $5 \mathrm{j}$ (à raison de $12 \mathrm{~h} / \mathrm{j}$ ) à $4{ }^{\circ} \mathrm{C}$, 


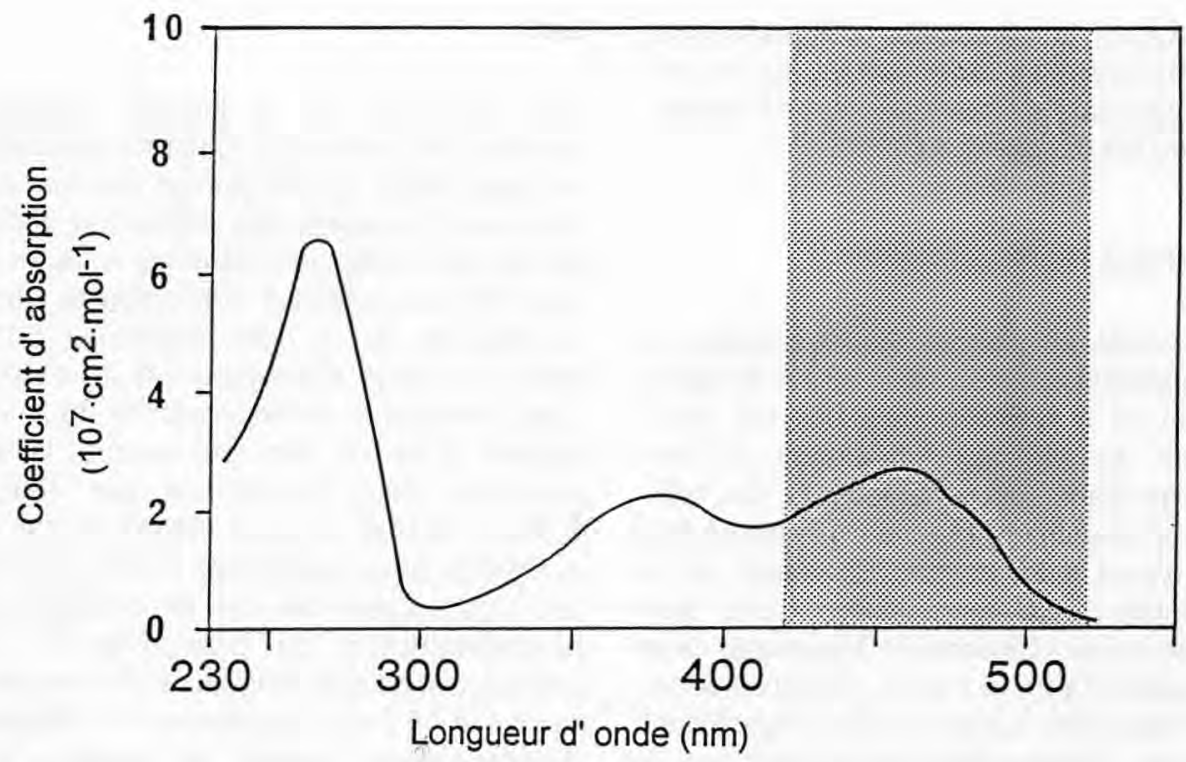

Fig 6. Spectre d'absorption de la riboflavine (Tagliaferri, 1989). Absorption spectrum of riboflavin.

sous $2000 \mathrm{~lx}$ au moyen des mêmes tubes fluorescents (Eberhard et Gallmann, 1991); - pour des laits entiers homogénéisés à diverses pressions et pasteurisés à diverses températures, contenus dans des bouteilles de verre incolore de $1 \mathrm{I}$, remplies aux $3 / 4$ : éclairement pendant $20 \mathrm{~h}$ à $8{ }^{\circ} \mathrm{C}$ sous $750 \mathrm{Ix}$ au moyen de tubes fluorescents de type blanc chaud, Philips type TLD 58/33W (Bosset et al, 1991);

- pour des beurres conditionnés dans divers matériaux d'emballage : éclairement pendant 2 semaines (à raison de $10 \mathrm{~h}$ par jour) à $8{ }^{\circ} \mathrm{C}$ sous $2300 \mathrm{Ix}$ à nouveau au moyen de tubes fluorescents de type blanc froid, Philips type TL33/40 W, puis pendant encore 2 semaines à $8^{\circ} \mathrm{C}$ à l'obscurité. Pour les échantillons de référence, 3 conditions de stockage à l'obscurité ont été prises en compte : a) 4 semaines à $8^{\circ} \mathrm{C}$; b) 3 semaines à $-18^{\circ} \mathrm{C}$ et c) 1 semaine à $8^{\circ} \mathrm{C}$ (Eyer, 1992, comm pers).

\section{EFFETS D'UNE EXPOSITION DU LAIT ET DES PRODUITS LAITIERS À LA LUMIÈRE}

Les chapitres qui suivent sont consacrés aux effets de la lumière sur divers composants et sur d'autres grandeurs mesurables du lait et des produits laitiers. $\mathrm{Ce}$ sujet a d'ailleurs fait l'objet de nombreux articles de revue auxquels on peut aussi se référer (Sattar et deMan, 1975; Shipe et al, 1978; Bradley, 1980; Dimick, 1982). Maints nutriments contenus dans les denrées alimentaires, dans le lait et les produits laitiers en particulier, sont photosensibles, tels les vitamines $A$ (et provitamine A), $B_{2}, B_{6}, B_{12}, D, K$, l'acide folique, les tocophérols, le tryptophane ainsi que les acides insaturés. Dans le cadre du présent travail, on s'intéressera plus particulièrement aux effets de la lumière sur les vitamines, sur les acides aminés libres, sur les 
peroxydes, sur quelques composés volatils responsables de la flaveur, sur la couleur ainsi que sur quelques autres composés du lait et des produits laitiers.

\section{Influence sur les vitamines}

Les pertes en vitamines correspondent à un appauvrissement, donc à une dévalorisation et à une dépréciation des nutriments. En fonction notamment de leur spectre d'absorption (tableau V), les différentes vitamines présentes réagissent diversement à la lumière. En raison de la présence, déjà mentionnée, d'une troisième bande d'absorption importante dans le visible (fig 6), la riboflavine constitue un cas particulier qui sera traité séparément ci-après. II est intéressant de noter que, à l'inverse, une exposition du lait enrichit ce dernier en vitamine D (Kon et Watson, 1936), procédé assez largement utilisé aux Etats-Unis vers 1920 (Burton, 1951).

\section{Lait}

Une exposition à la lumière blanche "froide" émise par des tubes fluorescents de type Philips 33 (longtemps recommandés pour l'éclairage des entrepôts) occasionne des pertes en vitamines $A, B_{6}$ et $E$ dans le lait pasteurisé non emballé. Pour la vitamine $A$, la perte avoisinait $50 \%$ après $6 \mathrm{~h}$ déjà (Desarzens et al, 1983). Ceci confirme la photosensibilité de la vitamine $A$ et de son précurseur, le $\beta$ carotène, déjà mentionnée par Sinha (1963), Hedrick et Glass (1975), Sattar et al (1977b) ainsi que deMan (1981) pour le lait. Ces auteurs ont mis en évidence la photodestruction du $\beta$-carotène de la graisse de lait aux longueurs d'onde inférieures à $465 \mathrm{~nm}$. Les pertes en vitamine A interviennent surtout en dessous de $415 \mathrm{~nm}$, un peu moins importantes entre 415 et $455 \mathrm{~nm}$ (Sattar et al, 1977a). deMan (1981) ainsi que Bartholomew et Ogden (1990) ont encore montré que.

Tableau V. Maxima d'absorption de diverses vitamines (anonyme, 1980).

Absorption maxima of some vitamins.

\begin{tabular}{|c|c|c|c|}
\hline Vitamine & Solvant & $\lambda \max (n m)$ & Remarques \\
\hline $\begin{array}{l}\text { A } \\
\beta \text {-Carotène } \\
D \\
\text { Tocophérol } \\
\mathrm{K}_{1} \\
\text { Acide ascorbique } \\
\mathrm{B}_{1} \\
\mathrm{~B}_{2} \\
\mathrm{~B}_{6}\end{array}$ & $\begin{array}{l}\text { Isopropanol } \\
\text { Cyclohexane } \\
\text { Cyclohexane } \\
\text { En solution alcoolique } \\
\text { En solution alcoolique } \\
\text { Cyclohexane } \\
\text { En milieu très acide } \\
\text { Après neutralisation } \\
\text { Dans } \mathrm{HCl} 0,1 \text { molaire } \\
\text { Dans } \mathrm{HCl} 0,1 \text { molaire } \\
\text { En solution aqueuse } \\
\text { Milieu acide } \\
\text { Milieu neutre } \\
\text { Milieu alcalin } \\
\text { En solution aqueuse } \\
\text { En solution aqueuse } \\
\text { Dans NaOH } 0,1 \text { mol/ }\end{array}$ & $\begin{array}{l}326 \\
328 \\
\text { Env } 456 \text { et } 484 \\
265 \\
292 \\
243,249,261,270 \\
\text { Environ } 245 \\
365 \\
200-300 \\
\text { Env } 245 \\
223,267,374,444 \\
291 \\
245 \text { et } 324 \\
309 \\
\text { Env } 278,361,550 \\
\text { Env 261 } \\
256,283,365\end{array}$ & $\begin{array}{l}\text { Minimum à } 255 \mathrm{~nm} \\
\text { Minima à } 254 \text { et } 285 \mathrm{~nm} \\
\text { Variable avec le pH }\end{array}$ \\
\hline
\end{tabular}


cette vitamine est plus photosensible si elle est ajoutée au lait que si elle y est présente naturellement. Un enrichissement en $\beta$-carotène diminue les pertes en vitamine $A$ dues à la photodégradation (Zahar et al, 1992). En cas d'enrichissement en vitamine $A$, le support (par ex : huile de beurre ou huile de noix de coco) ainsi que la forme utilisée (par ex : palmitate de rétinyle) jouent également un rôle (tableau VI). Les pertes en vitamine A mesurées dans le lait croissent avec l'éclairement, mais pas de façon directement proportionnelle (Gaylord et al, 1986).
Quant à la vitamine $B_{1}$, Ford (1967) ne signale aucune perte par suite d'une exposition d'un lait à la lumière solaire. Ferretti et al (1970) n'indiquent que $10 \%$ de perte dans un lait UHT stocké $90 \mathrm{j}$ sous un éclairage indirect comparativement à un lait identique conservé à l'obscurité. En revanche, Mohammad et al (1990) rapportent une diminution de la teneur en thiamine pouvant atteindre $40 \%$ dans un lait cru exposé $6 \mathrm{~h}$ durant à la lumière de tubes fluorescents comme d'ailleurs à la lumière du jour lors de la présence concomitante d'oxygène. L'irradiation d'une solution de thiamine pendant $5 \mathrm{j}$ au moyen d'une lampe à vapeur de mer-

Tableau VI. Influence de la lumière sur la teneur en vitamine $A$ du lait. Effect of light on the vitamin A content of milk.

\begin{tabular}{|c|c|c|c|c|c|c|}
\hline Lait & Vitamine A & Support & Récipient & $\begin{array}{l}\text { Conditions } \\
\text { exposition } \\
\text { lumière }\end{array}$ & Pertes en \% & \% Référence \\
\hline $\begin{array}{l}\text { Lait entier } \\
\text { Lait à } 2 \% \text { MG } \\
\text { Lait écrémé }\end{array}$ & $\begin{array}{l}\text { Native } \\
\text { ajoutée }\end{array}$ & & Plastique & $\begin{array}{l}30 \mathrm{~h} \text { sous } \\
2200 \mathrm{~lx}\end{array}$ & $\begin{array}{l}32 \\
73 \\
96\end{array}$ & $\begin{array}{l}\text { deMan, } \\
1981\end{array}$ \\
\hline $\begin{array}{l}\text { Lait entier } \\
\text { Laît à } 2 \% \text { MG } \\
\text { Lait écrémé }\end{array}$ & $\begin{array}{l}\text { Palmitate de } \\
\text { rétinyle }\end{array}$ & & Carton & $\begin{array}{l}48 \mathrm{~h} \text { sous } \\
1614 \mathrm{~lx}\end{array}$ & $\begin{array}{l}43 \\
47 \\
55\end{array}$ & $\begin{array}{l}\text { Gaylord } \\
\text { et al, } 1986\end{array}$ \\
\hline $\begin{array}{l}\text { Lait écrémé } \\
\text { Lait à } 2 \% \text { MG }\end{array}$ & $\begin{array}{l}\text { Palmitate } \\
\text { de rétinyle }\end{array}$ & $\begin{array}{l}\text { Huile de beurre } \\
\text { Huile de coco } \\
\text { Huile de maĩs } \\
\text { Huile d'arachide } \\
\text { Huile de beurre } \\
\text { Huile de coco } \\
\text { Huile de maĩs } \\
\text { Huile d'arachide }\end{array}$ & Verre & $\begin{array}{l}96 \mathrm{~h} \text { sous } \\
1614 \mathrm{Ix}\end{array}$ & $\begin{array}{l}\approx 40 \\
\approx 40 \\
\approx 80 \\
\approx 70 \\
\approx 30 \\
\approx 30 \\
\approx 60 \\
\approx 70\end{array}$ & $\begin{array}{l}\text { Zahar } \\
\text { et al, } 1986\end{array}$ \\
\hline Lait & $\begin{array}{l}\text { Palmitate de } \\
\text { rétinyle (=R) } \\
\text { R comme } \\
\text { concentré }\end{array}$ & Huile de beurre & Verre & $\begin{array}{l}32 \mathrm{~h} \text { sous } \\
4300 \mathrm{~lx}\end{array}$ & $\begin{array}{l}\approx 60 \\
\approx 95\end{array}$ & $\begin{array}{l}\text { Bartholomew } \\
\text { et Ogden } \\
1990\end{array}$ \\
\hline $\begin{array}{l}\text { Lait écrémé } \\
\text { Lait à } \% \% \text { MG }\end{array}$ & $\begin{array}{l}\text { Liposoluble } \\
\text { Hydrosoluble } \\
\text { Liposoluble } \\
\text { Hydrosoluble }\end{array}$ & & Polyéthylène & $\begin{array}{l}72 \mathrm{~h} \text { sous } \\
1076 \mathrm{~lx}\end{array}$ & $\begin{array}{l}58 \\
69 \\
35 \\
26\end{array}$ & $\begin{array}{l}\text { Fellman } \\
\text { et al, } 1991\end{array}$ \\
\hline
\end{tabular}


cure (raie à $254 \mathrm{~nm}$ ) entraîne la formation de composés perceptibles au nez (Van Dort et al, 1984). Le comportement de cette vitamine à l'égard de la lumière vient d'ailleurs de faire l'objet d'une récente publication ( $\mathrm{Ta}$ gliaferri et al, 1992a).

L'acide folique ne subit aucune altération significative dans un lait pasteurisé exposé durant $48 \mathrm{~h}$ à un éclairement artificiel de $2160 \mathrm{~lx}$, indépendamment du type d'emballage utilisé (carton, pots de plastique, sachets translucides souples) (Hoppner et Lampi, 1985). Outre celles dues au traitement thermique, des pertes occasionnées par une exposition à la lumière solaire ont pu être mises en évidence dans du lait stérilisé, préalablement purgé avec du gaz carbonique, ou inversement, saturé d'air. Une exposition au soleil cause également des pertes significatives en vitamines $B_{6}$ et $B_{12}$, mais pas en biotine ni en acide nicotinique (Ford, 1967).

La photolyse de la vitamine $\mathrm{C}$ a souvent été mentionnée dans la littérature (tableau VII). Elle dépend de plusieurs facteurs, en particulier de la source de lumière, de la durée et de l'intensité de l'exposition et du matériau d'emballage utilisé, ainsi que de la présence éventuelle de métaux (Sattar et al, 1977c) et d'oxygène, même en trace, qui accélère fortement la vitesse de cette photodestruction. Les pertes mesurées dans du lait pasteurisé peuvent même dépasser $90 \%$ après $30 \mathrm{~min}$ seulement d'exposition au soleil. En lumière artificielle, la couleur du tube fluorescent utilisé joue un rôle déterminant : plus le blanc est "chaud", moins les pertes sont importantes (Kiermeier et Waiblinger, 1969). De plus, le choix d'un emballage adéquat, peu perméable à l'oxygène, peut également retarder la photodestruction de la vitamine $\mathrm{C}$ du lait (tableau VIII). Selon Nordlund (1984), cette réaction suit une cinétique du 1 er ordre décrite par l'équation :

$$
A=A_{0} \cdot 10^{\left(-k \cdot t+1 \cdot t^{2}\right)}
$$

où:

$A=$ teneur en acide ascorbique après exposition à la lumière;

$A_{0}=$ teneur initiale en acide ascorbique;

$t=$ durée de l'exposition à la lumière;

$k, I=$ constantes.

Avec du lait pasteurisé conditionné dans des sachets souples (mis sur le marché helvétique en 1990), faits de plastique blanc légèrement translucide (puisque encore dépourvu d'une barrière contre la lumière), on a pu mesurer des pertes de plus de $50 \%$ en vitamine $\mathrm{C}$ après $12 \mathrm{~h}$ d'exposition à la lumière déjà (cf essai IV sous Rappel des principales conditions de travail adoptées précédemment par les auteurs). Aucune perte n'a en revanche été observée dans un lait conditionné dans une "brique» de TetraPak gardée comme témoin dans les mêmes conditions (fig 7) (Eberhard et Gallmann, 1991). Dans des conditions plus ménageantes (cf essai V,

Photoprotection:

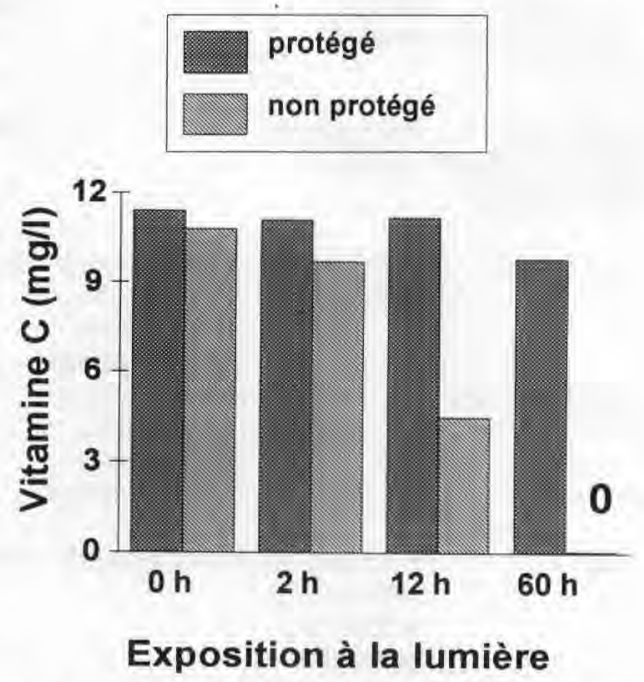

Fig 7. Teneur en vitamine $C$ d'un lait pasteurisé $\left(80^{\circ} \mathrm{C} / 15 \mathrm{~s}\right)$ exposé à la lumière.

Vitamin C content of pasteurised milk $\left(80^{\circ} \mathrm{C} /\right.$ 15 s) after light exposure (display cabinet). 
Tableau VII. Influence de l'exposition à la lumière sur la teneur en vitamine $\mathrm{C}$ de divers laits. Effect of light on vitamin C content of milk.

\begin{tabular}{|c|c|c|c|c|c|c|c|c|}
\hline \multirow[t]{2}{*}{ Référence } & \multirow[t]{2}{*}{ Lait } & \multirow[t]{2}{*}{ Emballage } & \multirow[t]{2}{*}{$\begin{array}{l}\text { Type de } \\
\text { lumière } \text { [d }\end{array}$} & \multirow[t]{2}{*}{$\begin{array}{l}\text { Conditions } \\
\text { [durée]/[temp] }\end{array}$} & \multirow{2}{*}{\multicolumn{2}{|c|}{$\begin{array}{c}\text { Teneur du } \\
\text { lait de départ } \\
\text { [mg/l] } \\
\text { Asc Asc + } \\
\text { Déhydr }\end{array}$}} & \multicolumn{2}{|c|}{$\begin{array}{c}\text { Perte } \\
\text { (\% du lait de départ) }\end{array}$} \\
\hline & & & & & & & Asc & $\begin{array}{c}\text { Asc + } \\
\text { Déhydroasc }\end{array}$ \\
\hline Chilson et al, 1949 & & & & $0,25 \mathrm{~h}$ & & & 100 & \\
\hline Andersen 1959 & $p$ & & $\begin{array}{l}\text { Lum jour } \\
\text { directe }\end{array}$ & $4 \mathrm{~h}$ & & 22,0 & & 56 \\
\hline $\begin{array}{l}\text { Hendrick } \\
\text { et de Moor, } \\
1962\end{array}$ & & Ve clair & $\begin{array}{l}\text { Lum jour } \\
\text { diffuse }\end{array}$ & $\begin{array}{l}1 \mathrm{~h} \\
3 \mathrm{~h}\end{array}$ & & & & $\begin{array}{l}78 \\
100\end{array}$ \\
\hline $\begin{array}{l}\text { Radema, } \\
1962\end{array}$ & $\mathrm{p}$ & Ve clair & $\begin{array}{l}\text { Tube } \\
\text { fluoresc: } \\
200,500 \\
1000,1500 \text {, } \\
2000 \mathrm{~lx}\end{array}$ & $6 \mathrm{~h}$ & & & & $\begin{array}{l}12,46 \\
68,86 \\
87\end{array}$ \\
\hline $\begin{array}{l}\text { Somogyi } \\
\text { et Ott, } 1962\end{array}$ & $\mathrm{p}$ & $\begin{array}{l}\text { Ve clair } \\
\text { Ve brun } \\
\text { Tetrapak }\end{array}$ & $\begin{array}{l}\text { Tube } \\
\text { fluoresc : } \\
\text { resp : blanc, } \\
\text { blanc-chaud, } \\
\text { jaune, rouge }\end{array}$ & $\begin{array}{l}6 \mathrm{~h} \\
\mathrm{~d}, \\
\mathrm{e}\end{array}$ & & & $\begin{array}{l}84,82,2 \\
18,16,10 \\
11,11,6\end{array}$ & $\begin{array}{l}0,17 \\
0,7 \\
, 5\end{array}$ \\
\hline Wodsak, 1960 & & & UV & & & & 0 & \\
\hline $\begin{array}{l}\text { Kiermeier } \\
\text { et Waiblinger, } 1969\end{array}$ & $p$ & PE & Lum jour & $5 \mathrm{~h}$ & 17,4 & 18,6 & 77 & 40 \\
\hline $\begin{array}{l}\text { Ferretti } \\
\text { et al, } 1970\end{array}$ & ui & & Lumière & $\begin{array}{l}30 \mathrm{j} / 20^{\circ} \mathrm{C} \\
30 \mathrm{j} / 37^{\circ} \mathrm{C} \\
90 \mathrm{j} / 20^{\circ} \mathrm{C} \\
90 \mathrm{j} / 37^{\circ} \mathrm{C}\end{array}$ & & & & $\begin{array}{l}24 \\
33 \\
45 \\
51\end{array}$ \\
\hline $\begin{array}{l}\text { Renner et } \\
\text { Baier, } 1971\end{array}$ & c & & $\begin{array}{l}\text { Soleil } \\
360 \mathrm{~W} \\
\text { UV }\end{array}$ & $\begin{array}{l}1 \mathrm{~h} \\
6 \mathrm{~h} \\
6 \mathrm{~h}\end{array}$ & $\begin{array}{l}19,5 \\
20,4 \\
18,0\end{array}$ & & $\begin{array}{l}45 \\
66 \\
26\end{array}$ & \\
\hline $\begin{array}{l}\text { Berlage- } \\
\text { Weinig, } 1983\end{array}$ & & $\begin{array}{l}\text { Ve clair } \\
\text { Ve opaq } \\
\text { Ca clair } \\
\text { Ca opaq }\end{array}$ & $\begin{array}{l}40 \mathrm{~W} \text { tube } \\
\text { fluoresc }\end{array}$ & $24 \mathrm{~h}$ & $\begin{array}{r}12,6 \\
12,8\end{array}$ & & $\begin{array}{r}54 \\
8 \\
7 \\
0\end{array}$ & \\
\hline $\begin{array}{l}\text { Schröder } \\
\text { et al, } 1985\end{array}$ & $p$ & $\begin{array}{l}\mathrm{Ca} \\
\mathrm{PE}\end{array}$ & $4000 \mathrm{~lx}$ & $\begin{array}{l}17 \mathrm{~h} / 7^{\circ} \mathrm{C} \\
9 \mathrm{~h} / 8^{\circ} \mathrm{C}\end{array}$ & $\begin{array}{l}18 \\
20\end{array}$ & $\begin{array}{l}15,5 \\
16,5\end{array}$ & $\begin{array}{l}18 \\
39\end{array}$ & $\begin{array}{r}9 \\
20\end{array}$ \\
\hline $\begin{array}{l}\text { Renner et al, } \\
1989\end{array}$ & & $\begin{array}{l}\text { Ve clair } \\
\text { Ve brun }\end{array}$ & $\begin{array}{l}700,1500 \\
2300 \mathrm{~lx}\end{array}$ & $12 \mathrm{~h}$ & & & & $\begin{array}{l}40-70 \\
20-40\end{array}$ \\
\hline
\end{tabular}

Abréviations : $\mathrm{c}=\mathrm{cru}, \mathrm{p}=$ pateurisé; $\mathrm{u}=$ upérisé; $\mathrm{i}=$ indirect; $\mathrm{Ve}=$ verre; $\mathrm{Ca}=\mathrm{carton} ; \mathrm{PE}=$ polyéthylène. Abbreviations: c: raw; p: pasteurised; $u$ : UHT-treated ; : indirect; Ve: glass; Ca: cardboard; PE: polyethylene. 
Tableau Vill. Teneur en acide ascorbique et en riboflavine du lait conditionné dans divers emballages après $24 \mathrm{~h}$ d'exposition à la lumière artificielle (Sattar et deMan, 1973).

Ascorbic acid and riboflavin contents of milk in different packages after $24 \mathrm{~h}$ fluorescent light exposure (1973).

\begin{tabular}{|c|c|c|c|c|c|c|}
\hline \multirow[t]{2}{*}{ Matériau d'emballa } & \multicolumn{3}{|c|}{ Acide ascorbique (mgh) } & \multicolumn{3}{|c|}{ Riboflavine (mg/l) } \\
\hline & $\begin{array}{c}\text { Avant } \\
\text { éclairement }\end{array}$ & $\begin{array}{l}\text { Eclairement } \\
\text { de } 1080 \mathrm{~lx}\end{array}$ & $\begin{array}{l}\text { Eclairement } \\
\text { de } 2160 \text { lx }\end{array}$ & $\begin{array}{c}\text { Avant } \\
\text { éclairement }\end{array}$ & $\begin{array}{l}\text { Eclairement } \\
\text { de } 1080 / x\end{array}$ & $\begin{array}{l}\text { Eclairement } \\
\text { de } 2160 \mathrm{Ix}\end{array}$ \\
\hline Sachet clair & 12,34 & 1,12 & 0,92 & 1,75 & 1,36 & 1,26 \\
\hline Sachet opaque & 12,34 & 10,74 & 10,22 & 1,75 & 1,74 & 1,73 \\
\hline Carton & 12,57 & 9,60 & 8,68 & 1,82 & 1,71 & 1,65 \\
\hline Pot de plastique & 12,34 & 1,70 & 1,28 & 1,80 & 1,60 & 1,56 \\
\hline
\end{tabular}

Rappel des principales conditions de travail adoptées précédemment par les auteurs), des pertes nettement plus faibles, de l'ordre de $33 \%$, ont été mesurées dans des laits ouverts exposés pendant $20 \mathrm{~h}$ à un éclairement de $750 \mathrm{~lx}$ (Bosset et al, 1991).

\section{Yoghourt nature}

Un même yoghourt nature a été conditionné dans 5 types d'emballages différents (pots ou gobelets de $180 \mathrm{~g}$ ). Seul le yoghourt conditionné dans du polystyrène transparent incolore a subi des pertes significatives en vitamines $A$ et $B_{12}$ à la suite d'une exposition à la lumière de type blanc froid des tubes Philips 33 (Bosset et Flückiger, 1986). Les valeurs obtenues à l'époque sont rappelées dans le tableau IX (les autres vitamines n'ont pas été dosées lors de cet essai). Pour les représentations graphiques, on se rapportera au travail original (Bosset et al, 1986a).

\section{Yoghourts avec divers ingrédients}

Dans le cadre d'essais complémentaires effectués avec des yoghourts fraise, mocca et chocolat, seules les vitamines A et $B_{2}$ ont été dosées (Tagliaferri, 1989). Après $18 \mathrm{j}$ d'entreposage à la lumière, aucune perte significative en vitamine A n'a pu être mesurée, même pas dans les gobelets en polystyrène transparent incolore. En ce qui concerne les yoghourts fraise, il en a été déduit que l'extrait de betterave rouge utilisé comme colorant semble agir comme barrière ou comme absorbant du point de vue optique, ce qui protège la vitamine A. Le spectre d'absorption d'un extrait contenant $1 \%$ de bétanine présente en effet un maximum à $530 \mathrm{~nm}$. Dans la région spectrale critique, soit entre 366 et $436 \mathrm{~nm}$, les taux d'absorption de la lumière se situent entre 25 et $40 \%$. Quant aux yoghourts mocca et chocolat, la stabilité de leur vitamine $\mathrm{A}$ est attribuée à leur teneur en antioxydants. Cette interprétation est d'ailleurs étayée par leur faible teneur en peroxydes même après une exposition à la lumière (Dieffenbacher et Trisconi, 1988).

\section{Rôle de la riboflavine et influence de la lumière sur la riboflavine}

De nombreuses études ont établi l'extrême photosensibilité de la vitamine $\mathrm{B}_{2}$ ainsi que 
Tableau IX. Pertes en vitamines dans du lait ouvert (Desarzens et al, $1983: 20000$ Ix), dans du yoghourt nature (Bosset et al, 1986a : $2000 \mathrm{~lx}$ ) et dans diverses sortes de yoghourt (Tagliaferri, 1989 : $2000 \mathrm{~lx}$ ) conditionnés dans divers emballages (lumière artificielle de type blanc froid : Philips 33 ). Vitamin losses in light-exposed unpacked milk (20 000 lux), natural yoghurt (2 $000 \mathrm{lux}$ ) and flavoured yoghurt (2000 lux) in different packages (artificial cool white light, Philips 33).

\begin{tabular}{|c|c|c|c|c|c|}
\hline Vitamine & $\begin{array}{c}\text { Verre } \\
\text { incolore }\end{array}$ & $\begin{array}{c}\text { Verre teinté } \\
\text { brun-rouge }\end{array}$ & $\begin{array}{l}\text { Polystyrène } \\
\text { incolore }\end{array}$ & $\begin{array}{l}\text { Polystyrène } \\
\text { brun-rouge }\end{array}$ & $\begin{array}{l}\text { Polystyrène } \\
\text { cartonné }\end{array}$ \\
\hline \multicolumn{6}{|l|}{ Vitamine A } \\
\hline Lait pasteurisé & * $\quad$ - & & & & \\
\hline Yog nature & * $\quad--$ & - & - - & + & + \\
\hline Yog fraise & & 0 & & & * $\quad-$ \\
\hline Yog mocca & & 0 & & & * 0 \\
\hline Yog chocolat & & 0 & & & $\begin{array}{l}* \\
*\end{array}$ \\
\hline \multicolumn{6}{|l|}{ Vitamine $\mathrm{E}$} \\
\hline Lait pasteurisé & -- & & & & \\
\hline \multicolumn{6}{|l|}{ Vitamin $B_{2}$} \\
\hline Lait pasteurisé & -- & & & & \\
\hline Yog nature & 0 & 0 & -- & 0 & 0 \\
\hline Yog fraise & & -- & & & $\star$ \\
\hline Yog mocca & & 0 & & & * \\
\hline Yog chocolat & & 0 & & & $\star$ \\
\hline \multicolumn{6}{|l|}{ Vitamine $\mathrm{B}_{6}$} \\
\hline $\begin{array}{l}\text { Vitamine } B_{12} \\
\text { Yog nature }\end{array}$ & -- & 0 & -- & & $\star$ \\
\hline
\end{tabular}

- $=$ analyses effectuées; $+=$ augmentation; 0 = pas de modification; $-=$ faible diminution; $--=$ forte diminution.

-:Analyses performed; +: increase; 0: no modification; -: slight decrease; --: significant decrease.

son rôle de photosensibilisateur dans le lait et les produits laitiers (Stamberg et Theophilus, 1945; Singleton et al, 1963; Kiermeier et Waiblinger, 1969; Singh et al, 1975; Maniere et Dimick, 1976; Parks et Allen, 1977; Sattar et al, 1977b; Allen et Parks, 1979; Desarzens et al, 1983; Nordlund, 1984; Toyosaki et al, 1984, 1988).

\section{Lait}

Les pertes en riboflavine sont également fonction du domaine spectral de la source utilisée, de la durée et de l'intensité de l'exposition, de la translucidité de l'emballage ainsi que de la température du produit, comme le montrent toute une série de tests effectués tant en lumière naturelle qu'en lumière artificielle (tableaux $X$ et $X I$ ). Deux heures d'exposition à la lumière solaire (Kiermeier et Waiblinger, 1969) suffisent pour photodégrader plus de la moitié de la riboflavine d'un lait ouvert, placé dans un récipient de verre transparent incolore. Sept heures d'exposition d'un lait pasteurisé ouvert, laissé sous une lumière 
Tableau $\mathrm{X}$. Influence de la lumière solaire directe et de la lumière du jour diffuse sur la teneur en vitamine $B_{2}$ du lait.

Effects of sunlight and diffuse daylight on vitamin $B_{2}$ content of milk.

\begin{tabular}{|c|c|c|c|c|c|c|}
\hline \multirow[t]{2}{*}{ Référence } & Lait & $\begin{array}{c}\text { Matériau } \\
\text { utilisé / }\end{array}$ & $\begin{array}{r}\text { Conditions } \\
\text { d'exposition } \\
\end{array}$ & Teneur & $\begin{array}{l}\text { Pertes } \\
\text { (\%) }\end{array}$ & Remarques \\
\hline & & emballage & $\begin{array}{cc}\text { Durée } & \text { Temp } \\
& \left({ }^{\circ} \mathrm{C}\right)\end{array}$ & $\begin{array}{l}\text { Lait de } \\
\text { part }(m g /)\end{array}$ & & \\
\hline
\end{tabular}

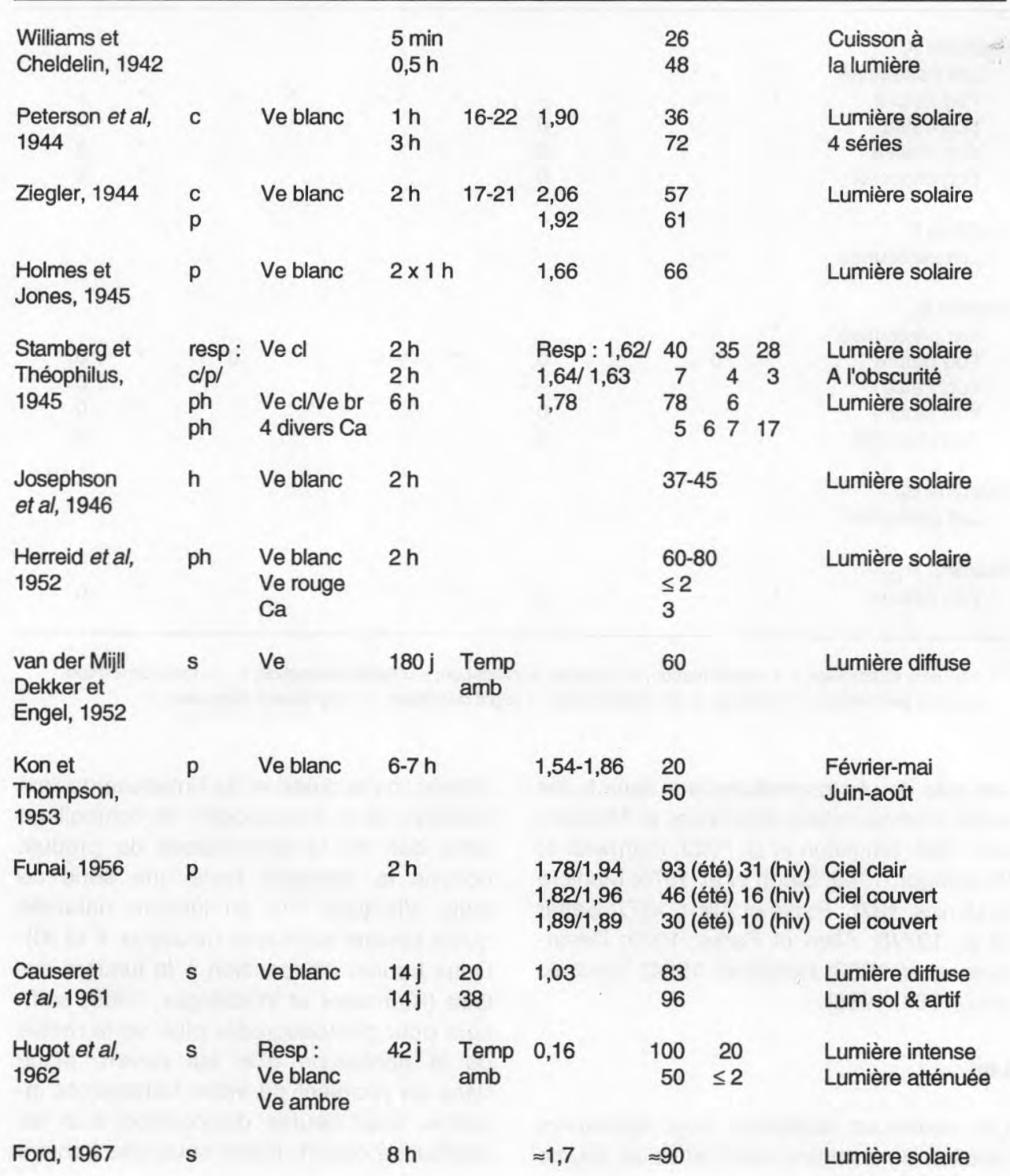




\begin{tabular}{|c|c|c|c|c|c|c|c|}
\hline $\begin{array}{l}\text { Kiermer et } \\
\text { Waiblinger, } 1969\end{array}$ & $p$ & PE & $6 \mathrm{~h}$ & $\approx 2,4$ & $\begin{array}{l}\approx 40 \\
\approx 90\end{array}$ & & $\begin{array}{l}\text { Lum jour diffuse } \\
\text { Lumière șolaire }\end{array}$ \\
\hline $\begin{array}{l}\text { Ferretti et al, } \\
\text { (1970) }\end{array}$ & ui & & $\begin{array}{l}30 j \\
90 j\end{array}$ & $\begin{array}{l}2037 \\
2037\end{array}$ & $\begin{array}{l}19 \\
26\end{array}$ & $\begin{array}{l}16 \\
27\end{array}$ & Lumière indirecte \\
\hline Paik et Kim, 1976 & & $\mathrm{Vecl}$ & $2 \mathrm{~h}$ & & 90 & & Lumière solaire \\
\hline Bates et al, 1985 & mat & PE & $7 \mathrm{~h}$ & & $\approx 50$ & & Lumière du jour \\
\hline $\begin{array}{l}\text { Mohammad } \\
\text { et al, } 1990\end{array}$ & $\begin{array}{l}\text { vac } \\
\text { mou } \\
\text { che } \\
\text { buf }\end{array}$ & $\begin{array}{l}\text { Récipient } \\
\text { opaque }\end{array}$ & $6 \mathrm{~h}$ & $\begin{array}{l}1,76 \\
3,42 \\
1,24 \\
1,32\end{array}$ & $\begin{array}{l}64 \\
66 \\
66 \\
64\end{array}$ & $\begin{array}{l}45 \\
49 \\
49 \\
48\end{array}$ & $\begin{array}{l}1^{\text {re }} \text { colonne } \\
\text { avec } \mathrm{O}_{2} \\
2^{\mathrm{e}} \text { colonne } \\
\text { sans } \mathrm{O}_{2}\end{array}$ \\
\hline $\begin{array}{l}\text { Sikka et al, } \\
1990\end{array}$ & $\begin{array}{l}\text { vac } \\
\text { buff }\end{array}$ & $\begin{array}{l}\text { Bouteilles } \\
\text { laquées } \\
\text { noir }\end{array}$ & $1 \mathrm{~h}$ & $\begin{array}{l}1,94 \\
1,59\end{array}$ & $\begin{array}{l}83 \\
77\end{array}$ & & $\begin{array}{l}\text { Lumière solaire; } \\
\text { base de réf : } 1 \\
\mathrm{~h} \text {, lait stocké } \\
\text { à temp amb }\end{array}$ \\
\hline
\end{tabular}

Abréviations : Laits : mat $=$ maternel; vac $=$ vache; mou $=$ mouton; che $=$ chèvre; buf $=$ buffle. $c=c r u, p=p a s t e u r i-$ sé; $\mathrm{h}=$ homogénéisé; $\mathrm{s}=$ stérilisé; $\mathrm{ui}=\mathrm{UHT}$ indirect. $\mathrm{Ve}=$ verre; $\mathrm{Ca}=$ carton; $\mathrm{PE}=$ polyéthylène; $\mathrm{cl}=\mathrm{clair} ; \mathrm{hiv}=$ hiver.

Abbreviations: Milks: mat: human; vac: cow; mou: sheep; che: goat; buf: buffalo. c: raw; p: pasteurised; h: homogenised; s: sterilized; ui: indirect UHT (ultra-high temperature). Ve: glass; Ca: cardboard; PE: polyethylene; cl: light; hiv: winter.

de type blanc froid de tubes fluorescents, type Philips 33 causent des pertes dépassant $75 \%$ (Desarzens et al, 1983). Dans des conditions d'éclairement beaucoup plus ménageantes (cf essai V, Rappel des principales conditions de travail adoptées précédemment par les auteurs), les pertes en riboflavine d'un lait entier ayant subi diverses homogénéisations et divers traitements thermiques demeurent néanmoins faibles (Tagliaferri et al, 1992b). Dans un autre essai, effectué avec un lait pasteurisé conditionné dans des sachets de plastique souples, légèrement translucides (non encore pourvus d'une barrière à la lumière), on a mesuré, après $60 \mathrm{~h}$ d'exposition à la lumière, une diminution de l'ordre de $20 \%$ de la teneur en riboflavine par rapport au même lait conservé dans une brique de carton de TetraPak (Eberhard et Gallmann, 1991). Le choix de l'emballage influence aussi considérablement les pertes en riboflavine d'un lait exposé à la lumière (tableau VIII). Selon Nordlund (1984), la photodestruction de la riboflavine suit une cinétique d'ordre 0 , avec une énergie d'activation de $23 \mathrm{~kJ} / \mathrm{mol}$ sous l'effet d'un éclairement très intense de 40 000-44000 lx (température comprise entre 10 et $50^{\circ} \mathrm{C}$ ). Selon d'autres auteurs (Singh et al, 1975; Gaylord et al, 1986; Palanuk et al, 1988; Sattar et al, 1977b), il s'agirait plutôt d'une réaction du 1 er ordre sous l'effet d'un éclairement moindre compris entre 1600 et $5400 \mathrm{~lx}$ (température comprise entre 2 et $25^{\circ} \mathrm{C}$ ). La forte diffusion de la lumière par les globules gras pourrait expliquer la photolyse moins prononcée de la vitamine $B_{2}$ dans un lait entier que dans un lait partiellement écrémé $(2 \%)$ et dans un lait maigre (Gaylord et al, 1986) après un éclairement de $1614 \mathrm{IX}$ 
Tableau XI. Influence de la lumière artificielle sur la teneur en vitamine $\mathrm{B}_{2}$ du lait. Effect of fluorescent light on vitamin $B_{2}$ content of milk.

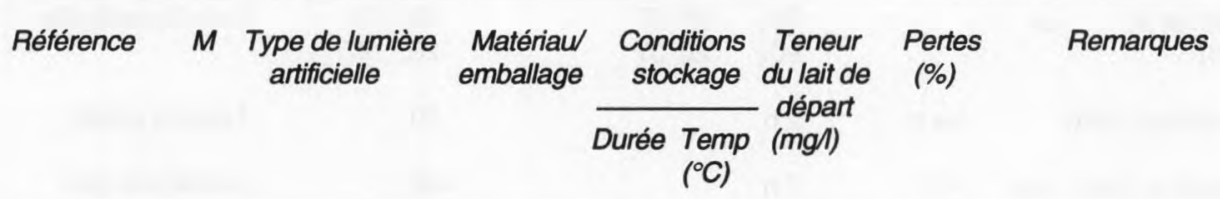

\begin{tabular}{|c|c|c|c|c|c|c|c|c|c|c|}
\hline $\begin{array}{l}\text { Somogyi } \\
\text { et Ott, } 1962\end{array}$ & $\mathrm{p}$ & $\begin{array}{l}\text { Resp : } \\
\text { blanc, blanc- } \\
\text { chaud, jaune, } \\
\text { rouge }\end{array}$ & $\begin{array}{l}\text { Ve blanc } \\
\text { Ve br } \\
\mathrm{Ca}\end{array}$ & $6 \mathrm{~h}$ & & & $\begin{array}{l}40 \\
24 \\
14\end{array}$ & $\begin{array}{rr}26 & 16 \\
21 & 10 \\
9 & 8\end{array}$ & $\begin{array}{ll}6 & 17 \\
0 & 14 \\
8 & 11\end{array}$ & \\
\hline Dimick, 1976 & $p$ & Blanc-froid & Plastique & $5 j$ & 7 & 2,8 & 17 & & & \\
\hline $\begin{array}{l}\text { Fukumoto et } \\
\text { Nakashima, } \\
1975\end{array}$ & & Blanc & $\begin{array}{l}\text { Boîte de } \\
\text { Pétri }\end{array}$ & $3 \mathrm{~h}$ & & & $\begin{array}{l}60 \\
20\end{array}$ & 3010 & r & $\begin{array}{l}\text { Sans filtre } \\
\text { Filtre bleu, br, } \\
\text { rouge }\end{array}$ \\
\hline $\begin{array}{l}\text { Hedrick et } \\
\text { Glass, } 1975\end{array}$ & $p$ & 1614 ex & $\begin{array}{l}\text { Ca } \\
\text { Plastique }\end{array}$ & $\begin{array}{l}5,10 \\
24 h\end{array}$ & 4 & $\begin{array}{l}1,66 \\
1,67\end{array}$ & $\begin{array}{l}3 \\
5\end{array}$ & $\begin{array}{ll}4 & 3 \\
7 & 8\end{array}$ & $\begin{array}{l}3 \\
8\end{array}$ & $n=11$ \\
\hline deMan, 1978 & & $\begin{array}{l}2200 \mathrm{~lx} \text {, resp : } \\
\text { blanc-froid, } \\
\text { blanc-froid + filtre, } \\
\text { blanc-chaud }\end{array}$ & $\begin{array}{l}6 \text { diff } \\
\text { emb } \\
\text { Ca } \\
\text { Plastique }\end{array}$ & $48 h$ & 4 & & $\begin{array}{l}13- \\
17 \\
19\end{array}$ & $\begin{array}{ll}-28 & \\
11 & 15 \\
13 & 17\end{array}$ & & \\
\hline $\begin{array}{l}\text { Hoskin et } \\
\text { Dimick, } 1979\end{array}$ & $p$ & $1076 \mathrm{~lx}$ & $\begin{array}{l}\text { Ve, PC, } \\
P E\end{array}$ & $72 \mathrm{~h}$ & 7 & & 27 & 1310 & 0 & \\
\hline $\begin{array}{l}\text { Desarzens } \\
\text { et al, } 1983\end{array}$ & $p$ & $20000 \mathrm{~lx}$ & & $7 \mathrm{~h}$ & & 1,9 & $\approx 85$ & & & Méthode : HPLC \\
\hline $\begin{array}{l}\text { Fanelli } \\
\text { et al, } 1985\end{array}$ & & $\begin{array}{l}35 \mathrm{~W} \\
\text { blanc-froid }\end{array}$ & $\mathrm{Ca}$ & $16 \mathrm{~h}$ & 1,5 & & $\approx 55$ & & & \\
\hline $\begin{array}{l}\text { Schröder } \\
\text { et al, } 1985\end{array}$ & $p$ & $4000 \mathrm{~lx}$ & $\begin{array}{l}\mathrm{PE} \\
\mathrm{Ca}\end{array}$ & $90 \mathrm{~h}$ & 7 & 1,5 & $\begin{array}{r}31 \\
0\end{array}$ & 37 & & 2 essais \\
\hline $\begin{array}{l}\text { Gaylord } \\
\text { et al, } 1986\end{array}$ & & $1614 \mathrm{Ix}$ & $\mathrm{Ca}$ & $48 \mathrm{~h}$ & 4 & & $\begin{array}{l}55 \\
64 \\
70\end{array}$ & & & $\begin{array}{l}\text { Lait entier } \\
\text { Lait à } 2 \% \text { MG } \\
\text { Lait écrémé }\end{array}$ \\
\hline $\begin{array}{l}\text { Ford et al, } \\
1986\end{array}$ & $p$ & $4000 \mathrm{~lx}$ & Ve & $14 j$ & 4,5 & $\approx 1,5$ & $\approx 80$ & $\approx 60$ & & $\begin{array}{l}\text { Past } 72^{\circ} \mathrm{C} \\
82^{\circ} \mathrm{C}\end{array}$ \\
\hline Hoskin, 1988 & $p$ & $4300 \mathrm{~lx}$ & $\begin{array}{l}\mathrm{PE}, \\
\mathrm{PE}+\text { Alu }\end{array}$ & $72 \mathrm{~h}$ & 6 & $\begin{array}{l}0,84 \\
0,79\end{array}$ & $\begin{array}{r}13 \\
1\end{array}$ & & & \\
\hline $\begin{array}{l}\text { Renner } \\
\text { et al, } 1988\end{array}$ & $\mathrm{p}$ & $\begin{array}{l}7001500 \\
2300 \mathrm{~lx}\end{array}$ & Vecl & $12 \mathrm{~h}$ & & & $25-$ & & & \\
\hline
\end{tabular}




\begin{tabular}{|c|c|c|c|c|c|c|c|}
\hline $\begin{array}{l}\text { Mohammad } \\
\text { et al, } 1990\end{array}$ & $\begin{array}{l}\text { vac } \\
\text { mou } \\
\text { che } \\
\text { buf }\end{array}$ & $\begin{array}{l}\text { Récipient } \\
\text { opaque }\end{array}$ & $6 \mathrm{~h}$ & $\begin{array}{l}1,76 \\
1,42 \\
1,24 \\
1,32\end{array}$ & $\begin{array}{l}56 \\
59 \\
59 \\
58\end{array}$ & $\begin{array}{l}39 \\
39 \\
39 \\
36\end{array}$ & $\begin{array}{l}1^{r e} \text { colonne } \\
\text { avec } \mathrm{O}_{2} \text {. } \\
2^{e} \text { colonne } \\
\text { sans } \mathrm{O}_{2}\end{array}$ \\
\hline $\begin{array}{l}\text { Sikka et al, } \\
1990\end{array}$ & $\begin{array}{l}\text { vac } \\
\text { buf }\end{array}$ & $\begin{array}{l}\text { Bouteilles } \\
\text { laquées } \\
\text { noir }\end{array}$ & $\begin{array}{l}2 \mathrm{~h} \\
1 \mathrm{~h}\end{array}$ & $\begin{array}{l}1,94 \\
1,59\end{array}$ & $\begin{array}{l}26 \\
22\end{array}$ & & $\begin{array}{l}\text { Base de réf : } 1 \mathrm{~h} \text {, } \\
\text { lait stocké à } \\
\text { temp ambiante }\end{array}$ \\
\hline
\end{tabular}

Abréviations : $c f$ légende du tableau X. $\mathrm{PC}=$ Polycartonate; $\mathrm{br}=\mathrm{brun}$. Abbreviations: cf legend to table $X ; P C$ : polycarbonate; br: brown.

pendant $48 \mathrm{~h}$. Une étude bibliographique vient d'ailleurs d'être consacrée à cette question (Tagliaferri et al, 1992b).

\section{Yoghourt nature}

Une coloration brun-rouge tant du polystyrène que du verre contribue, en partie du moins, à protéger la riboflavine du yoghourt nature de sa photodestruction puisqu'elle est à même de filtrer efficacement la lumière précisément dans la bande où cette vitamine absorbe (figs 5 et 6 ). Un emballage cartonné est évidemment encore meilleur puisque sa translucidité est quasi nulle. Le cas inverse est celui du gobelet de polystyrène transparent incolore, dans lequel les pertes en riboflavine peuvent atteindre $90 \%$ en $18 \mathrm{j}$ (Bosset et Flückiger, 1986). Tagliaferri (1989) a confirmé ces résultats en mettant en évidence des pertes de l'ordre de $55 \%$ après $21 \mathrm{j}$.

\section{Yoghourts avec divers ingrédients}

La teneur en riboflavine d'un yoghourt fraise a diminué pratiquement de moitié après $18 \mathrm{j}$ de stockage à la lumière dans un gobelet de polystyrène, mais pas dans un pot de verre transparent teinté en brunrouge. On en conclut que, à l'inverse de ce que l'on observe avec la vitamine $A$, le jus de betterave rouge ajouté à cette sorte de yoghourt pour renforcer sa coloration n'a pas d'effet photoprotecteur particulier sur la riboflavine. En revanche, la teneur en cette vitamine demeure quasi inchangée dans les yoghourts mocca et chocolat. On doit en déduire que les extraits de café et de chocolat, riches en pigments colorés, offrent une réelle protection contre la lumière (Tagliaferri, 1989).

\section{Fromage}

Le fromage, source également importante de riboflavine, peut aussi se révéler sensible à la lumière. II est en outre fréquemment mis en vente sous la forme de petites portions préemballées dans une feuille de plastique ultra-mince et parfaitement transparente. II est exposé dans des présentoirs ou des vitrines généreusement illuminés, dans lesquels il est conservé plus longtemps que le lait. Deger et Ashoor (1987) ont étudié la photodégradation de la riboflavine dans le fromage. Ils ont choisi le cheddar comme modèle, qu'ils ont découpé en tranches de $0,6 \mathrm{~cm}, 2,5 \mathrm{~cm}$ et $5,1 \mathrm{~cm}$ d'épaisseur et qu'ils ont stockées pendant $12 \mathrm{j}$ à 5 et $10^{\circ} \mathrm{C}$ sous des éclairements de 538,1614 et $5380 \mathrm{~lx}$. Ils ont mesuré des pertes en vitamine $B_{2}$ augmentant avec l'intensité de l'exposition à la lumière. Ces pertes dépassaient $40 \%$ dans les morceaux emballés sous film de plasti- 
que transparent sous $5380 \mathrm{~lx}$. L'épaisseur du morceau ne semble pas influencer les résultats, peut-être en raison de la faible profondeur de pénétration de la lumière dans un milieu aussi compact. Paradoxalement et de façon inexplicable, une augmentation de la teneur en riboflavine semble avoir été constatée dans des morceaux de fromage de types cheddar et colby de 3 à $4,1 \mathrm{~cm}$ d'épaisseur exposés durant 14 j à un éclairement compris entre 1076 et $1829 \mathrm{~lx}$. Inversement, une diminution de 1 à $12 \%$ est signalée dans des fromages râpés ou coupés en fines lamelles entreposés dans les mêmes conditions.

\section{Influence sur les protéines et les acides aminés libres}

Les réactions photo-oxydatives peuvent aussi influencer les protéines lactiques ainsi que les acides aminés libres (Dimick et Kilara, 1983). Pour les protéines lactosériques, cela se traduit par une agrégation. Une hydrolyse des peptides peut également avoir lieu sous l'effet tant de la lumière solaire que de la lumière artificielle. Parmi les acides aminés ainsi libérés, on peut citer la méthionine, le tryptophane, la cystéine, l'histidine et la tyrosine (Bosset et al, 1986a, b; Dimick et Kilara, 1983). Sous l'effet de la lumière, la méthionine est transformée en méthional (Allen et Parks, 1975) et le tryptophane en kynurénine et en N-méthylkynurénine (Kanner et Fennema, 1987).

La lumière fluorescente ne modifie pas les teneurs en acides aminés libres et totaux dans des laits stockés dans des récipients de verre, de matière fibreuse, de carton ou de plastique (Dimick, 1973; Hedrick et Glass, 1975). Si la composition des protéines lactosériques de type $\beta$ lactoglobuline et $\alpha$-lactalbumine ne s'est que peu altérée sous l'influence d'une exposition de $72 \mathrm{~h}$ en lumière artificielle, celle de la fraction des immunoglobulines en a été plus considérablement modifiée (Dimick, 1976). En présence de riboflavine, une illumination intensive des protéines lactosériques ( $\beta$-lactoglobuline et $\alpha$ lactalbumine) peut générer des fractions protéiques à haut poids moléculaire et hydrolyser certains ponts peptidiques (Gilmore et Dimick, 1979). Elle peut également générer des anions peroxides (Korycka-Dahl et Richardson, 1979).

\section{Influence sur la formation de peroxydes}

Un indicateur relativement sensible souvent utilisé pour mettre en évidence des modifications oxydatives ou photooxydatives des graisses et des huiles alimentaires est leur indice de peroxyde. Cet indicateur permet en effet de déterminer photométriquement le degré d'oxydation des acides gras insaturés. L'analyse est basée sur la formation d'un complexe coloré avec le $\mathrm{Fe}$ (III) obtenu par oxydation du $\mathrm{Fe}$ (II) par les peroxydes (Dieffenbacher et Lüthi, 1986). Ces derniers sont euxmêmes générés par l'oxydation des doubles liaisons desdits acides gras insaturés par l'oxygène. Cet indice est néanmoins moins sensible et plus tardif dans sa réponse que lesdites altérations de la flaveur ("off-flavoum) que l'on cherche précisément à détecter. Les peroxydes sont en effet des substances labiles qui produisent surtout des composés carbonylés dont le seuil de perception tant olfactif que gustatif est généralement très bas.

\section{Yoghourt nature et yoghourts avec divers ingrédients}

Dans le yoghourt nature, la formation de peroxydes sous l'effet de la lumière dépend étroitement de l'emballage utilisé (fig 8). Dans un matériau incolore, l'indice de peroxyde croît au cours de l'exposition à la lumière, plus fortement dans un maté- 
A) Nature

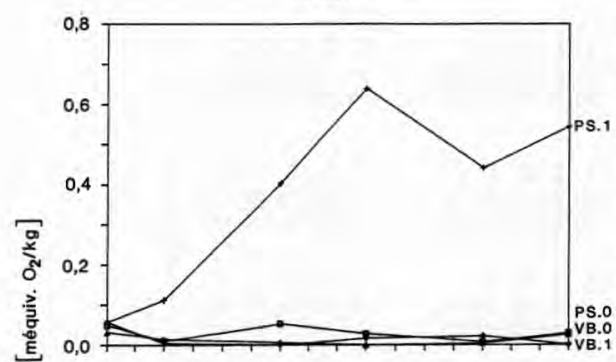

C) Mocca

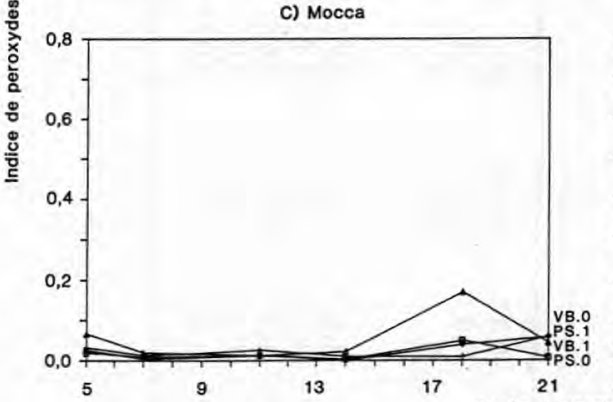

B) Fraise

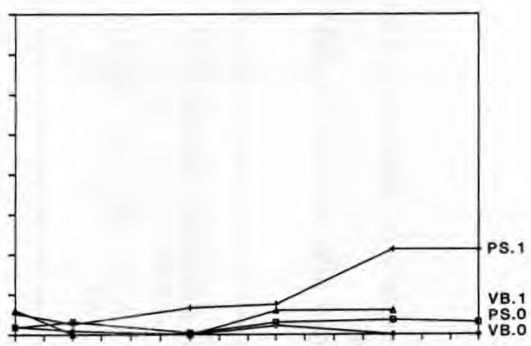

D) Chocolat

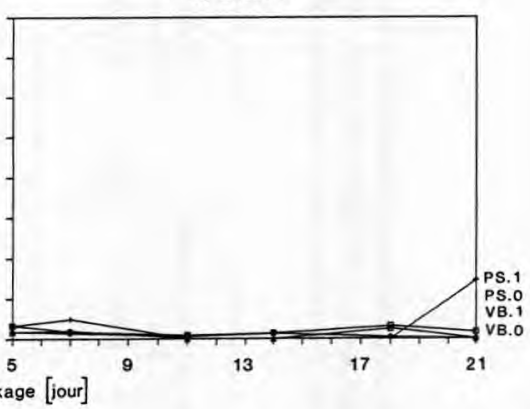

Fig 8. Indice de peroxyde de divers yoghourts stockés dans les conditions suivantes : PS. $0=$ polystyrène/obscurité; PS.1 = polystyrène/lumière; VB. 0 = verre brun/obscurité; VB.1 = verre brun/lumière (Dieffenbacher et Trisconi, 1988).

Peroxide values of yoghourt stored in the following conditions : PS. $0=$ polystyrene/dark; PS.1 = polystyrene/light; VB. 0 = brown glass/dark; VB.1 = brown glass/light.

riau perméable à l'oxygène comme le polystyrène que dans du verre. Dans le premier matériau cité, l'indice de peroxyde a passé de 0,06 à $0,6 \mathrm{meq} \mathrm{O}_{2} / \mathrm{kg}$ sous l'effet de la lumière, alors qu'il est resté constant dans les échantillons témoins gardés à l'obscurité. L'augmentation sensible de cet indice dans le polystyrène brun, mais pas dans le verre brun exposés à la lumière peut à nouveau s'expliquer par la différence de perméabilité à l'oxygène de ces 2 matériaux. L'indice de peroxyde d'un yoghourt fraise n'a pas varié autant que celui d'un yoghourt nature. Quant aux yoghourts mocca et chocolat, leur indice de peroxyde est demeuré pratiquement inchangé, même s'ils sont conditionnés dans l'emballage le moins protecteur de tous ceux testés (le polystyrène transparent incolore), ce qui prouve l'action antioxydante de certains de leurs ingrédients (Dieffenbacher et Trisconi, 1988).

\section{Beurre}

Un beurre, emballé dans 10 matériaux différents, a été exposé à la lumière artificielle sous différents éclairements, puis stocké pendant 4 semaines à $4^{\circ} \mathrm{C}(\mathrm{Em}$ mons et al, 1986a). L'indice de peroxyde était systématiquement plus élevé à la surface du produit qu'à l'intérieur, à 2 exceptions près correspondant à l'éclairement le plus faible (tableau XII). L'indice de peroxyde n'a pas augmenté proportionnellement à la durée de l'exposition à la lu- 
Tableau XII. Intensité du goût d'oxydé, évaluation de la flaveur et indice de peroxyde (différences mesurées entre la surface et l'intérieur du beurre après diverses conditions d'exposition à la lumière artificielle et 4 semaines de stockage à $5{ }^{\circ} \mathrm{C}$ ) (Emmons et al, 1986a).

Oxidised flavour intensity, flavour score and peroxide values - differences between the surface and the interior of butter after exposure to different lighting conditions and 4 wk storage at $5^{\circ} \mathrm{C}$.

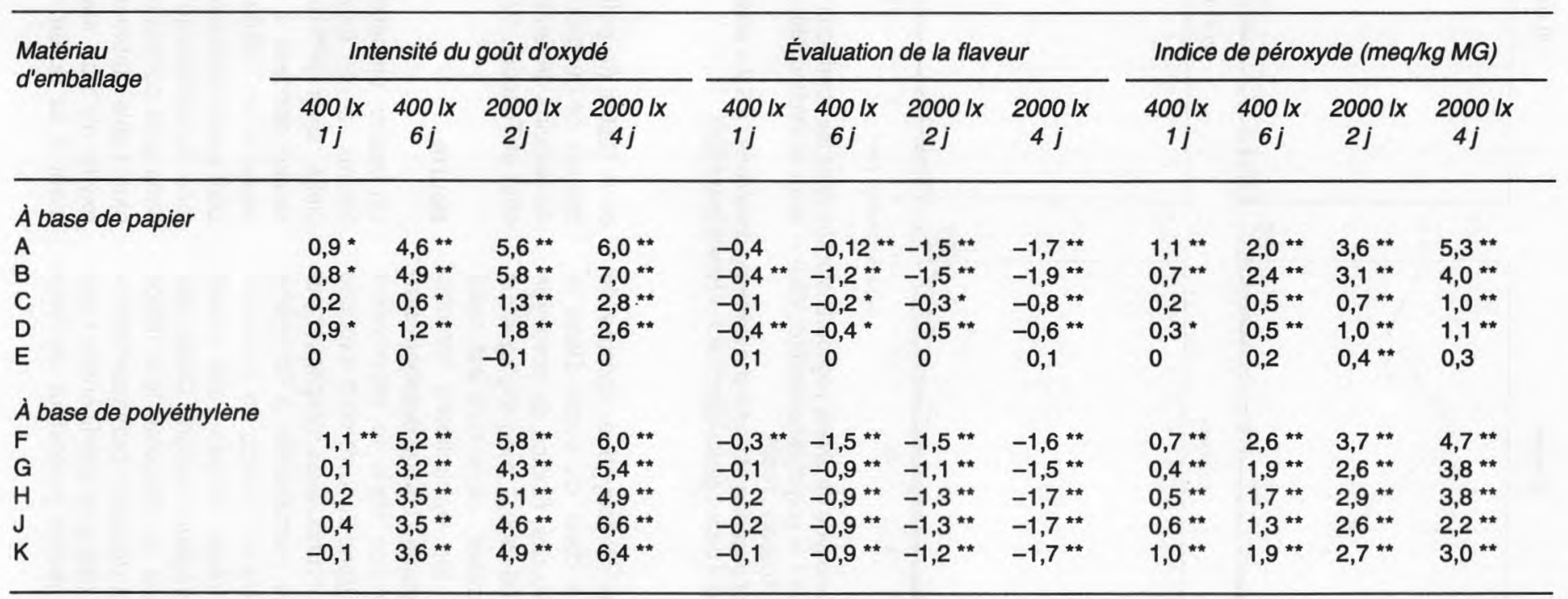

* $p<0,05 ;{ }^{* *} p<0,01$. 
mière. D'après Luby et al (1986a), l'indice de peroxyde après $20 \mathrm{j}$ d'exposition à la lumière est plus élevé à la surface que dans l'ensemble du bloc de beurre. Dans des beurres placés dans des présentoirs à $5^{\circ} \mathrm{C}$ sous un éclairage artificiel de $648 \mathrm{~lx}$, cet indice a également augmenté. Une relation de linéarité a pu être établie entre son accroissement et l'éclairement correspondant (Foley et al, 1971). Dans d'autres essais effectués avec 6 emballages différents, seul le beurre emballé dans une feuille d'aluminium a maintenu constant son indice de peroxyde après $15 \mathrm{j}$ sous lumière artificielle (Luby et al, 1986b).

\section{Fromage}

En utilisant le test à l'acide thiobarbiturique (TBA), il n'a pas été possible de trouver une différence significative entre la valeur mesurée à la surface d'un cheddar (enrichi en fer) exposé à la lumière artificielle et celle mesurée avec un fromage de référence conservé à l'obscurité (Zhang et Mahoney, 1990).

\section{Influence sur la formation de composés volatils désagréables}

Les altérations de la composition chimique du lait et des produits laitiers se traduisent en définitive par une altération de leur flaveur. Elles sont à l'origine du défaut de goût dit "de lumière", qui a beaucoup été étudié ces dernières années (Shipe et al, 1978).

\section{Lait}

La sensibilité à la lumière varie fortement d'une sorte de lait à l'autre. Le défaut de goût caractéristique d'une exposition à la lumière apparaît de façon plus prononcée dans un lait maigre que dans un lait entier
UHT ou dans une crème à café UHT (Desarzens et al, 1983), ce qui s'explique sans doute par leur différence de pouvoir de réflexion et de diffusion de la lumière incidente.

Dans des laits cru et pasteurisé exposés $30 \mathrm{~min}$ au soleil, les teneurs en maints composés volatils désagréables tels que l'acétaldéhyde, le propanal, le $n$-pentanal et l'hexanal augmentent d'un facteur 2 à 7 (Jenq et al, 1988). À côté de ces composés, Bassette (1976) a également étudié le comportement de composants générés par voie microbiologique comme l'acétone et la butanone - qui ne semblent pas modifiés ainsi que le comportement du sulfure de méthyle. Cet auteur a confirmé que ce dernier composé est fortement produit par une exposition à la lumière artificielle, mais paradoxalement pas par la lumière solaire, pourtant plus énergétique. Sous l'influence de cette dernière, la teneur en acétaldéhyde augmente plus dans un lait maigre que dans un lait entier pasteurisé.

Dans les laits maigre et entier traités par UHT et exposés $4 \mathrm{~h}$ durant à la lumière artificielle, on a constaté un défaut de goût dont l'importance croît avec la durée de l'exposition (Desarzens et al, 1983). Après 2 h déjà, un lait conditionné dans un sachet de plastique souple faiblement translucide (cf essai IV sous Rappel des principales conditions de travail adoptées précédemment par les auteurs) a été décrit à l'aide des termes de "goût de suif", "oxydé", "goût de lumière" et “impur" (Eberhard et Gallmann, 1991). Des laits homogénéisés à différentes teneurs en matière grasse $(3,25 \%, 2 \%$ et $0 \%$ ) exposés $24 \mathrm{~h}$ à un éclairement de 2200 Ix dans des récipients de plastique ont été jugés comme très altérés comparativement à des laits de référence gardés à l'obscurité, et cela d'ailleurs indépendamment de leur teneur en matière grasse (deMan, 1980). Inversement et de façon paradoxale, Olsen et Ashoor (1987) ne si- 
gnalent aucune modification de la flaveur de laits provenant de commerces de détail et soumis à des éclairements de 129$1076,215-1076$ ou $915-4304$ Ix durant 3-7 j. Ces auteurs prétendent que ni la saison, ni le type d'emballage (matière synthétique ou fibreuse), ni la taille du récipient, ni même la teneur en matière grasse ne jouent de rôle.

\section{Yoghourt nature et yoghourts avec divers ingrédients}

La production de quelques aldéhydes et méthylcétones (de C-3 à C-11) a été étudiée dans des yoghourts nature et fraise conditionnés dans des gobelets de polystyrène transparent incolore et des pots de verre brun, de $180 \mathrm{~g}$ de contenance, exposés à la lumière (cf essai III, Rappel des principales conditions de travail adoptées précédemment par les auteurs) (Bosset et Gauch, 1988). On y a mesuré surtout une augmentation de leur teneur en propanal, en butanal, en hexanal et/ou en hexanone-2. Dans le yoghourt nature, un léger enrichissement en butanone-2, en pentanal et/ou en pentanone-2 de même qu'en heptanal et/ou en heptanone-2 (composés non résolus chromatographiquement) a également pu être établi. En revanche, aucun accroissement significatif n'a pu être mis en évidence pour le méthional, ce qui pourrait être dû à des problèmes analytiques (petit pic avec chevauchement d'un grand pic très voisin). L'acétaldéhyde et l'acétone, dont l'origine dans les produits fermentés frais est microbiologique, n'ont pas semblé varier sous l'effet de la lumière.

Dans des yoghourts nature soumis pendant $4 \mathrm{~h}$ à des éclairements de 10000 , 25000 et $50000 \mathrm{~lx}$, un "goût de lumière" caractéristique est apparu après $3 \mathrm{~h}$ avec les 2 éclairements les plus intenses (de Moor et Hendrickx, 1970). Des tests en tri- angle combinés à des tests de préférence ont démontré que les altérations de la flaveur des yoghourts nature et, dans une moindre mesure, des yoghourts contenant divers ingrédients dépendent aussi bien de l'emballage utilisé que de la durée du stockage à la lumière (Daget, 1989). La figure 9 indique l'évolution des différences perçues en cours de stockage entre les échantillons exposés à la lumière et ceux correspondants gardés à l'obscurité comme témoins. Les altérations les plus prononcées ont été perçues dans les yoghourts nature exposés à la lumière dans les gobelets de polystyrène transparent incolore. Celles des yoghourts fraise étaient un peu moins marquées, mais néanmoins significatives après $2 \mathrm{j}$. La cinétique de cette altération de la flaveur s'exprime par les régressions logarithmiques suivantes:

pour le yoghourt nature: $y=0,49+1,135 \ln x$ (coefficient de corrélation $r=0,996$ )

pour le yoghourt fraise : $y=0,925+0,572 \ln x$ (coefficient de corrélation $r=0,767$ )

où $x$ est la durée du stockage exprimée en jours. Dans les pots de verre brun, ces 2 sortes de yoghourts présentent une meilleure stabilité de leur flaveur.

En revanche, il n'est apparu aucune altération significative de la flaveur des yoghourts mocca et chocolat, même pas dans l'emballage le plus transparent. Seuls quelques dégustateurs ont apprécié ces deux sortes de yoghourts comme "moins bons" et "moins aromatiques» après $9 \mathrm{j}$, et comme "nettement moins bons" après $13 \mathrm{j}$. Aucune mention de "goût de lumière" ou "d'oxydé" n'a été faite, ce qui confirme clairement le pouvoir protecteur de leurs antioxydants (cf Influence de la lumière sur la formation de peroxydes) (Daget, 1989).

\section{Beurre}

Les beurres dans lesquels a été mesurée une augmentation de l'indice de peroxyde 
A) Nature

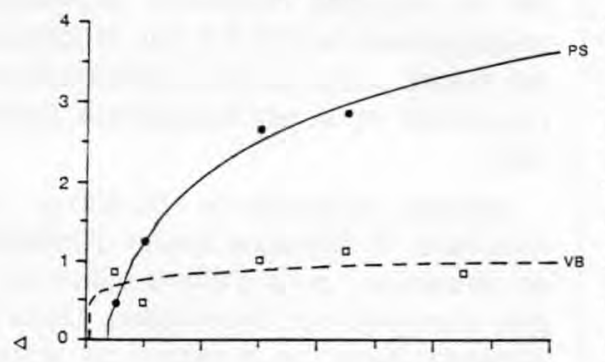

巡

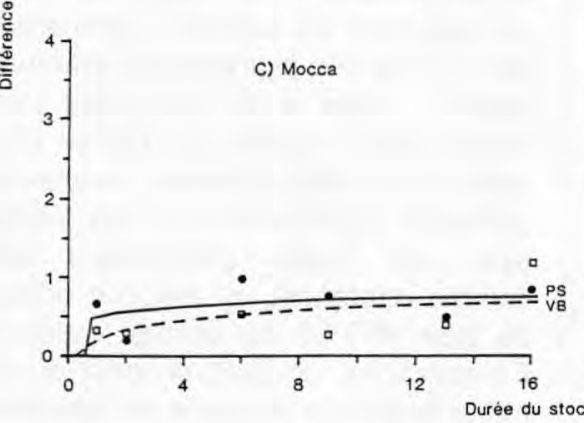

B) Fraise

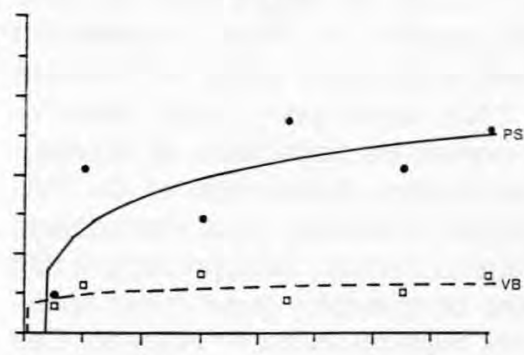

D) Chocolat

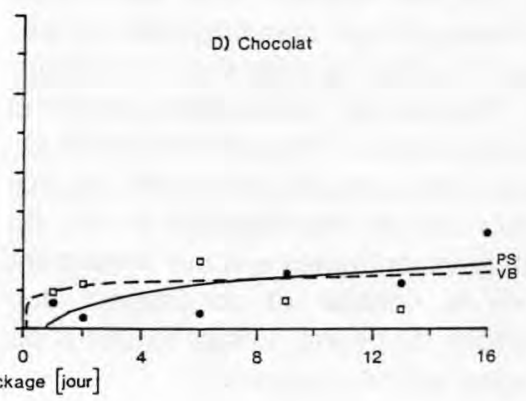

Fig 9. Cinétique de l'altération de la flaveur de divers yoghourts stockés à la lumière : PS = polystyrène transparent incolore; VB = verre brun (Daget, 1989).

Kinetics of flavour changes in yoghurt stored under light: $P S=$ transparent non-tinted polystyrene; VB = brown glass.

consécutive à une exposition à la lumière artificielle ont également été taxés comme plus fortement oxydés. Après fusion, le défaut d'oxydé a été constaté de façon plus prononcée dans le sérum du beurre que dans la matière grasse proprement dite (Foley et al, 1971). Lors de l'étude déjà citée (cf Influence de la lumière sur la formation de peroxydes) réalisée sur un beurre conditionné dans 10 sortes d'emballages différents (Emmons et al, 1986a), ce défaut de goût n'a été que peu perçu après 1 j sous $400 \mathrm{~lx}$ (tableau XII). En revanche dans les 3 autres conditions de stockage ( 6 j sous $400 \mathrm{~lx}, 2$ et $4 \mathrm{j}$ sous $2000 \mathrm{~lx}$ ), le défaut d'oxydé était présent, mais paradoxalement plus marqué à l'intérieur qu'à l'exté- rieur du beurre, constatation confirmée d'ailleurs par l'évaluation sensorielle de la flaveur. Parmi les emballages testés, la feuille d'aluminium (tableau XII, emballage E) n'offrait pourtant aucune translucidité. Dans une autre étude des mêmes auteurs (Emmons et al, 1986b), 66 échantillons de beurre ont été prélevés en fonction de leur position (en l'occurrence dessus et devant) dans des piles stockées dans 6 entrepôts. 7 de ces 66 échantillons présentaient un goût d'oxydé nettement plus intense que les beurres du précédent essai, exposés 2 j sous 2000 lx (Emmons et al, 1986b). Sur la base de ces travaux, la valeur limite de $1 \%$ de translucidité a été adoptée pour l'emballage du beurre au Canada. 
L'effet de la lumière sur la flaveur du beurre a aussi été étudié dans le cadre d'essais propres lors d'une comparaison de divers emballages (taille et matériau) (Eyer, 1992, comm pers). Cette étude visait à évaluer les possibilités de substitution des feuilles d'aluminium et de PVC par d'autres matériaux plus ménageants pour l'environnement, mais présentant des garanties comparables quant à leur opacité et leur imperméabilité à l'oxygène. Ces essais ont été réalisés dans des conditions d'entreposage standardisées correspondant à celles rencontrées en pratique (cf VI, Rappel des principales conditions de travail adoptées précédemment par les auteurs). Les examens sensoriels (saveur et odeur) ont été effectués par un jury de dégustateurs entraînés qui ont également jugé de la couleur et de l'aspect des échantillons de beurre. Les conclusions de ces essais sont les suivantes:

- petites portions de 10-20 g de beurre: les petites barquettes usuellement utili- sées en Suisse peuvent être remplacées par un matériau composite (polystyrène/ polyéthylène) de 0,4-0,6 mm d'épaisseur, qui assure une protection suffisante contre l'oxydation et la photooxydation (tableau XIII).

- plaques de beurre de $100-200 \mathrm{~g}$ : pour remplacer la classique feuille d'emballage en aluminium, on a d'abord utilisé du papier aluminisé par évaporation. Dans une seconde étape, on a même pu renoncer au traitement de surface à l'aluminium en recourant à une pigmentation adéquate du papier. L'essai a été concluant, mais a montré que la qualité du papier utilisé à cette fin était déterminante : aucune photoaltération significative n'a été constatée avec une feuille d'aluminium (utilisée comme référence), ni avec un emballage de type HIFI LS 50 exempt d'aluminium. En revanche, un goût d'oxydé ou de lumière ou encore de suif a été détecté avec un emballage d'une autre provenance, également exempt d'aluminium.

Tableau XIII. Effet protecteur contre l'oxydation du beurre conditionné en petites portions dans diverses barquettes de $0,4 \mathrm{~mm}$ d'épaisseur (test sensoriel).

Protection against oxidation in different small portion butter packages, with container wall thickness of $0.4 \mathrm{~mm}$ (sensory assessment).

\begin{tabular}{|c|c|c|c|c|c|c|}
\hline Gran & Matériau & Matériau & Note & s du test senso & & Perte \\
\hline $\begin{array}{l}\text { portion } \\
\text { (g) }\end{array}$ & $\begin{array}{l}\text { pour la } \\
\text { feuille }\end{array}$ & $\begin{array}{c}\text { pourle } \\
\text { couvercle }\end{array}$ & $\begin{array}{l}\dot{A} \text { l'obscurité } \\
\text { (nb de points) }\end{array}$ & $\begin{array}{l}\text { A la lumière } \\
\text { (nb de points) }\end{array}$ & Témoin & de poids \\
\hline
\end{tabular}

\begin{tabular}{lllllll}
\hline 20 & ABS & PET-alu & 10,5 goût de vieux, jaunâtre & 7 goût de suif, jaunâtre & 11,0 & 4,2 \\
20 & ABS & Operflex & 10,5 idem & 7 idem & 11,0 & 4,2 \\
20 & PS/PE & PET-alu & 11,25 & 9 lég goût de suif & 11,25 & 1,4 \\
& & & 10,75 & 11,25 & 1,7 \\
10 & ABS & PET-alu & 11,0 & 11,0 & 11,25 & 1,1 \\
10 & PS/PE & PET-alu & 11,25 & 10,25 & 11,0 & 1,3 \\
10 & PS/PE & PET-alu & 11,0 & & & \\
\hline
\end{tabular}

Échelle à 12 points : 1 = très mauvais, 12 = très bon; $A B S=$ acrylnitrile-butadiène-styrène; $P S / P E=$ monofeuille de polystyrène/polyéthylène; $\mathrm{PET}$-alu = polyéthylène-téréphtalate; Operflex = polypropylène.

12-point scale: 1 = very poor; 12 = very good; $A B S$ : acrynitrile-butadiene-styrene; PS/PE; polystyrene/polyethylene single sheet; PET-alu: polyethylene-terephthalate; Operilex: polypropylene. 
- barquettes de $200 \mathrm{~g}$ : la grande barquette en matière synthétique avec doublure externe cartonnée des parois ("jupe") et du fond s'est révélé parfaitement utilisable. Du point de vue de la photoprotection, le seul point faible d'un tel emballage est la jointure de carton entre le fond et la partie latérale.

\section{Fromage}

Un éclairement d'un fromage sous 538 , 1614 et $5380 \mathrm{~lx}$ pendant $12 \mathrm{j}$ en lumière artificielle ne semble pas avoir induit de modification de saveur ou d'odeur perceptible (Deger et Ashoor, 1987). Kristoffersen et al (1964) mentionnent en revanche une perte de la qualité organoleptique d'un cheddar et d'un emmental ( "Swiss type cheese") exposés à la lumière, perte pourtant comparable à celle observée dans les échantillons de référence gardés à l'obscurité. Les qualificatifs suivants ont été utilisés :

- pour le cheddar gardé à la lumière: oxydé, métallique et brûlé;

- pour l'emmental gardé à la lumière: acide butyrique, impur et oxydé;

- pour le cheddar gardé à l'obscurité: acide, fermenté, petit-lait et chiffon mouillé;

- pour l'emmental gardé à l'obscurité: acide et étable.

\section{Autres produits laitiers}

Un babeurre exposé $4 \mathrm{j}$ à un éclairement de $2420 \mathrm{~lx}$ en lumière artificielle de type blanc froid n'a pas permis de mettre en évidence une altération de sa flaveur due à une photooxydation (Hoskin, 1989).

Au $\mathrm{pH}$ de 6,7, un lactosérum neutralisé obtenu à partir d'un lait pasteurisé est plus sensible à la lumière que le lait pasteurisé ou le lait maigre correspondant. Un lactosérum dialysé est encore plus photosensible, ce qui s'explique certainement par sa forte translucidité ainsi que par la bonne solubilité de la riboflavine dans ce milieu (Jenq et al, 1988).

\section{Influence sur la couleur}

La couleur des produits laitiers change sous l'action de la lumière. Une des explications possibles est à rechercher dans la photodestruction de certains de leurs constituants fortement colorés tels que la riboflavine, le $\beta$-carotène et la vitamine $A$, qui influencent directement les composantes a et $b$ de la couleur selon Hunter. Une autre explication peut être fournie par la modification de la structure diffusante desdits produits laitiers (photo-agglomération, photolyse, etc) qui influence directement la composante L (luminance ou brillance) (cf. aussi : Influence de la lumière sur les protéines et les acides aminés libres), donc indirectement les composantes $a$ et $b$ des produits laitiers.

\section{Lait et crème à café}

À côté de la photodégradation de la riboflavine, Toba et al (1980) mentionnent encore que la photodégradation de composés fortement fluorescents tels que la tyrosine et le tryptophane est probablement aussi à l'origine du changement de la couleur des produits laitiers. La profondeur de pénétration de la lumière incidente dans le milieu dépend étroitement de sa turbidité (rapport entre l'énergie transmise et l'énergie réfléchie). Ainsi les composantes $L$, $a$ et $b$ d'un lait écrémé varientelles plus fortement que celles d'un lait entier ou même d'une crème à café lors du stockage à la lumière. Un lait cru est en revanche plus stable qu'un lait homogénéisé (Desarzens et al, 1983).

L'exposition à la lumière de divers laits et produits laitiers ouverts (laits maigre, 
cru, pasteurisé, lait condensé et crème à café) se traduit en général par une diminution de leur composante $L \quad(\rightarrow$ moins brillante), par une augmentation de leur valeur algébrique négative a $(->$ moins verte) et par une diminution de leur composante positive b ( $\rightarrow$ moins jaune). Les variations de ces composantes $L$, $a$ et $b$ se traduisent graphiquement par des sigmoïdes en fonction de la durée de l'illumination, ce qui pourrait indiquer l'existence d'une chaîne de réactions. Ces valeurs se stabilisent après un certain temps (Desarzens et al, 1983).

\section{Yoghourt nature}

Pour le yoghourt nature, l'altération des couleurs $L$, $a$ et $b$ sous l'effet de la lumière a varié d'un emballage à l'autre. Dans le cas des gobelets en position usuelle, c'està-dire couvercle en haut, l'importance des variations $(\Delta=$ différence entre l'échantillon exposé à la lumière et l'échantillon gardé comme référence à l'obscurité) des composantes colorées variaient dans l'ordre suivant :

$-\Delta \mathrm{L}$ (luminance décroissante) :

$\mathrm{PS} / \mathrm{K}<\mathrm{PS} / \mathrm{B}=\mathrm{G} / \mathrm{B}<\mathrm{G} / \mathrm{U}<\mathrm{PS} / \mathrm{U}$

- $\Delta \mathrm{a}$ (composante verte décroissante) :

$\mathrm{PS} / \mathrm{K}=\mathrm{PS} / \mathrm{B}<\mathrm{G} / \mathrm{B}<\mathrm{G} / \mathrm{U}<\mathrm{PS} / \mathrm{U}$

- $\Delta b$ (composante jaune décroissante) :

$\mathrm{PS} / \mathrm{K}=\mathrm{PS} / \mathrm{B}<\mathrm{G} / \mathrm{B}<\mathrm{G} / \mathrm{U}<\mathrm{PS} / \mathrm{U}$.

Le facteur de photoprotection offert par l'emballage doit donc être ordonné dans un ordre inverse, soit : $\mathrm{PS} / \mathrm{K}=$ polystyrène cartonné $>P S / B=$ polystyrène teinté brun $>\mathrm{G} / \mathrm{B}=$ verre teinté brun $>\mathrm{G} / \mathrm{U}=$ verre incolore $>\mathrm{PS} / \mathrm{U}=$ polystyrène incolore. En stockant les gobelets en position renversée (couvercle contre le bas), on peut montrer en outre que la lumière, fortement atténuée par la photodiffusion, pénètre jusqu'au centre de la masse du yoghourt (Bosset et al, 1986a, b; Desarzens, 1988).

\section{Yoghourts avec divers ingrédients}

Avec des yoghourts mocca et chocolat exposés 21 j sous $2000 \mathrm{~lx}$, la luminance (naturellement faible) a augmenté, même jusqu'à l'intérieur de la masse, mais plus faiblement. Les composantes $\mathbf{a}$ et $\mathbf{b}$ de ces mêmes yoghourts n'ont en revanche pas varié, ni dans l'ensemble de leur masse; ni dans leur centre, indépendamment des conditions de l'exposition et de l'emballage utilisé. Dans le yoghourt fraise, on a en revanche observé une nette diminution de ces composantes (Desarzens, 1988).

\section{Fromage}

Une exposition de fromage pendant $12 \mathrm{j}$ sous un éclairement de $1614 \mathrm{~lx}$ ou plus se traduit par une modification de sa couleur déjà perceptible à l'oeil (Deger et Ashoor, 1987).

\section{Influence sur d'autres constituants}

Dans le yoghourt nature, les grandeurs suivantes sont restées insensibles à l'action de la lumière: la valeur du $\mathrm{pH}$, la pression partielle du gaz carbonique $\left(\mathrm{pCO}_{2}\right)$, la teneur totale en gaz carbonique, l'acide lactique $D$ et $L$, la teneur en 4 acides carboxyliques et celle en amines biogènes (Bosset et al, 1986a, b). La valeur du pH n'a d'ailleurs varié dans aucun des yoghourts étudiés (Desarzens, 1988).

À la surface d'un beurre exposé à la lumière artificielle $(1500 \mathrm{~lx})$, Luby et al (1986a) ont mis en évidence la présence de 2 oxycholestérols $(7 \alpha-$ et $7 \beta$ hydroxycholestérols) par chromatographie en couche mince. La concentration des produits d'oxydation du cholestérol était plus faible dans les échantillons de beurre emballés que dans ceux dépourvus d'emballage (Luby et al, 1986b). 
Sander et al (1989) ont également trouvé certains oxycholestérols dans du cheddar conservé sous forme de poudre après un éclairement de $1611 \mathrm{~lx}$ pendant 12 semaines à la lumière artificielle. Les teneurs en cholestane-3 $\beta$-ol, $5 \beta, 6 \beta$-époxyde et en $7 \beta$-hydroxycholestérol sont restées cons-

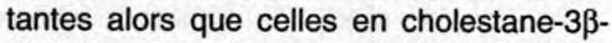
ol, $5 \alpha, 6 \alpha$-époxyde et en 7-cétocholestérol ont atteint un maximum à la $3^{e}$ semaine pour décroître ensuite jusqu'à la $12^{\mathrm{e}}$ semaine.

\section{Comparaison des cinétiques et des seuils de détection des diverses altérations}

Au cours du stockage à la lumière, diverses altérations de nature chimique, biochimique, chimico-physique et sensorielle se produisent dans le lait et les produits laitiers. Ces altérations ont été discutées en détail, mais individuellement, dans les chapitres précédents. Dans le cadre de l'étude de la photoprotection du yoghourt nature, ces modifications sont apparues chronologiquement dans l'ordre suivant (fig 10) : après 2 j déjà, les premières altérations de la flaveur (Daget, 1989); après environ $4 \mathrm{j}$, les premières pertes significatives en vitamines $B_{2}$ (Tagliaferri, 1989); après approximativement $7 \mathrm{j}$ à la lumière, la modification de la composante b de la couleur (Desarzens, 1988) et l'accroissement de l'indice de peroxyde (Dieffenbacher et Trisconi, 1988). Les cinétiques de ces altérations semblent être du premier ordre (Daget, 1989). On déduit de cet ordre d'apparition que les examèns sensoriels semblent être plus rapides et plus sensibles pour détecter la photodégradation du lait et des produits laitiers que les analyses chimico-physiques (Bosset et Flückiger, 1989).

Le fait que certains composés carbonylés tel que propanal, butanal, pentanal, pentanone, hexanal et hexanone (Bosset et
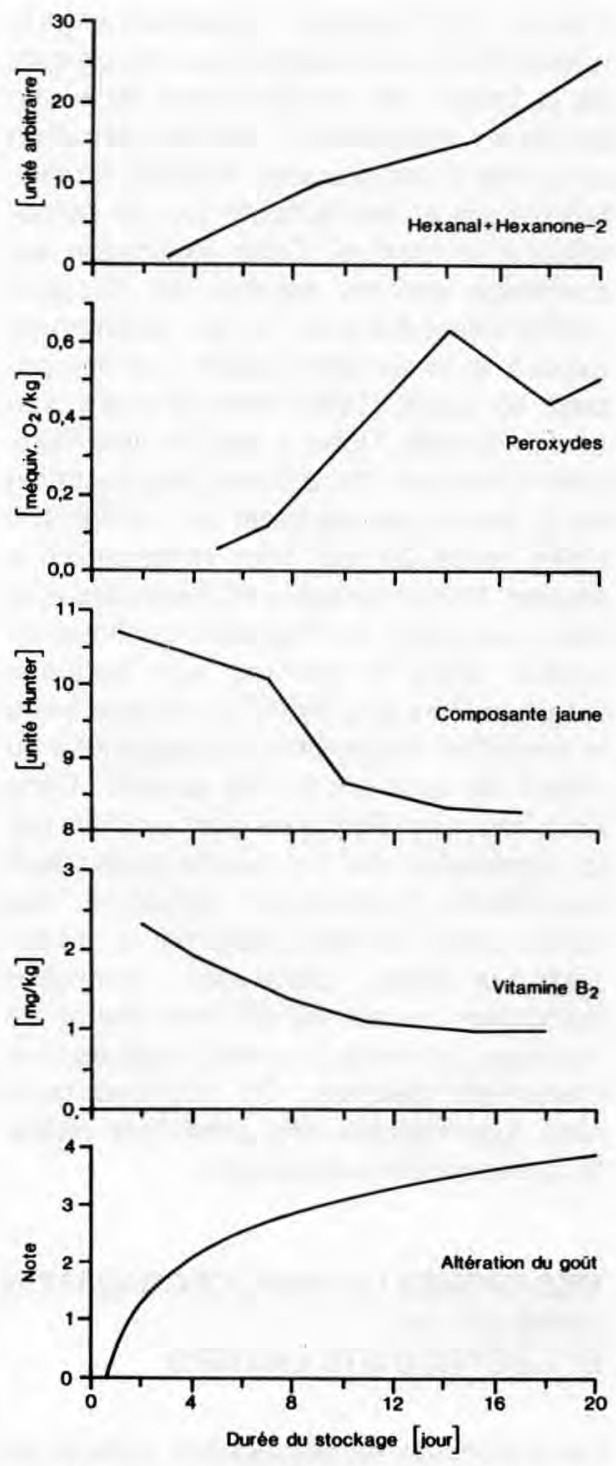

Fig 10. Comparaison du "temps de réponse" et de la sensibilité de divers indicateurs de photodégradation à l'exemple du yoghourt nature stocké sous lumière artificielle dans du polystyrène transparent incolore (Bosset et Flückiger, 1989).

Comparison of the response times and sensitivities of photooxidation indicators demonstrated by the example of natural yoghurt exposed to light in non-tinted transparent polystyrene cups. 
Gauch, 1988) semblent apparaître analytiquement en même temps que les défauts de la flaveur est probablement dû à une périlleuse extrapolation de leur détection au temps 0 , les premiers dosages au GCMS n'ayant eu lieu qu'au $3^{e}$ jour de l'exposition à la lumière. Cette explication est confirmée par les travaux de Bassette (1976) effectués avec un lait directement exposé à la lumière solaire comme par ceux de Daget (1989) dans le cadre d'un essai accéléré. Dans le premier cas, Bassette a mesuré d'abord une augmentation de la teneur en pentanal qui atteint 150 $\mu \mathrm{g} / \mathrm{kg}$ après $20 \mathrm{~min}$ pour redescendre à environ $110 \mu \mathrm{g} / \mathrm{kg}$ après 20 nouvelles min, alors que celle de l'hexanal continue de croître. Dans le cas du test accéléré, Daget montre une étroite corrélation entre la formation de pentanal et l'apparition du défaut de goût qui lui est associé. Dans les 2 cas, ces aldéhydes sont produits par la dégradation des peroxydes (peracides), eux-mêmes produits par l'oxydation des acides gras insaturés. Les produits initiaux (radicaux libres, peroxydes, composés carbonylés ou autres) de cette chaîne de réactions ne sont pourtant toujours pas clairement identifiés. On suppose qu'ils sont responsables des premières altérations sensorielles observées.

\section{MÉCANISMES DE PHOTODÉGRADATION DANS LE LAIT ET LES PRODUITS LAITIERS}

Les processus de dégradation dans le lait et les produits laitiers sont nombreux et complexes. La riboflavine y participe comme photosensibilisateur, l'oxygène, comme source d'oxygène activé (singulet ${ }^{1} \mathrm{O}_{2}$ ou triplet ${ }^{3} \mathrm{O}_{2}$ ), la méthionine ainsi que les acides gras insaturés, comme réactants pour diverses réactions chimiques.

Le défaut de flaveur ("off-flavour") provoqué par l'exposition à la lumière paraît avoir 2 origines distinctes, mettant en jeu 2 groupes de réactions de photodécomposition différentes. Les premières réactions sont rapides et ont pour substrats les protéines et les acides aminés libres. Leurs produits de réaction sont généralement caractérisés par les termes de "goût de lumière ou de soleil, de brûlé, de choux (cuit) ou de champignon". Les secondes réactions sont probablement plus tardives et impliquent les acides gras insaturés. On désigne généralement leurs produits de réaction par les termes de "goût d'oxydé ou d'oxydé, goût de papier ou de carton ou de couvercle, métallique, de suif ou huileux" (Azzara et Campbell, 1992).

La riboflavine, tout comme la vitamine C, est très photosensible et participe de façon déterminante aux altérations causées par la lumière, la photodestruction de l'acide ascorbique étant d'ailleurs étroitement associée à la photosensibilisation de la riboflavine.

\section{La lumière et la riboflavine}

Comme déjà indiqué précédemment, la riboflavine participe de façon déterminante aux mécanismes qui conduisent à la formation et à l'apparition des goûts d'oxydé et de lumière. Selon Richardson et Korycka-Dahl (1983), d'autres réactions sont associées à la photodécomposition de la riboflavine, dans lesquelles l'oxygène ainsi que d'autres substrats peuvent intervenir (fig 11). Par absorption de photons, le photosensibilisateur (riboflavine) est excité. La suite du mécanisme de décomposition dépend entre autres des concentrations relatives des réactants potentiels. En présence d'une concentration relativement élevée en oxygène, la riboflavine réduite retourne dans sa forme initiale avec formation d'oxygène actif. Dans une seconde étape, la riboflavine peut alors être détruite par cet oxygène actif. 


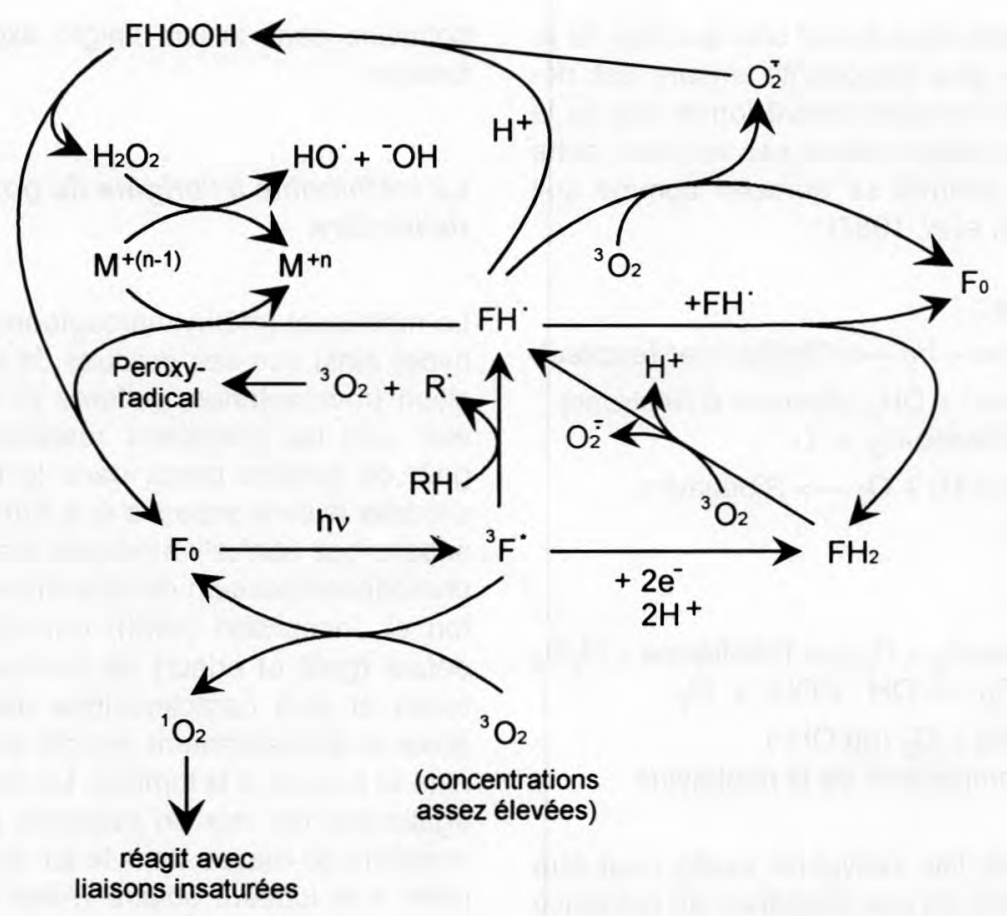

Légende:

produits oxygénés

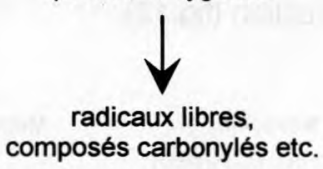

$\begin{array}{ll}\mathrm{F}_{0} & =\text { riboflavine } \\ \mathrm{FH} & =\text { radical semiquinone } \\ { }^{1} \mathrm{O}_{2} & =\text { oxygène singulet } \\ { }^{3} \mathrm{O}_{2} & =\text { oxygène triplet } \\ \mathrm{HO} & =\text { radical hydroxyle } \\ \mathrm{RH} & =\text { substrats du lait } \\ \mathrm{R}^{\cdot} & =\text { radicaux libres } \\ \mathrm{h} & =\text { photons } \\ M^{+(n-1)}, M^{+n} & =\text { chélates métalliques }\end{array}$

Fig 11. Réactions possibles par photocatalyse impliquant la riboflavine (schéma proposé par Richardson et Korycka-Dahl, 1983, modifié).

Possible photocatalytic reactions involving riboflavin.

Toyosaki et al $(1987,1988)$ ont effectué une étude détaillée de la photolyse de la riboflavine dans le lait. Ils ont démontré que cette réaction est plus complexe dans le lait qu'en solution aqueuse pure. Dans le lait, cette photolyse est une combinaison d'un mécanisme de dégradation classique de la riboflavine pure en solution et d'un 
mécanisme dans lequel une quantité de riboflavine plus importante encore est détruite par l'oxygène activé formé lors de la première phase. Selon ces auteurs, cette réaction pourrait se dérouler comme suit (Toyosaki et al, 1987) :

1re phase :

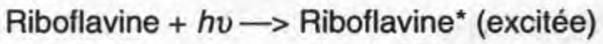

Riboflavine* $+\mathrm{DH}_{2}$ (donneur d'électrons)

$\rightarrow$ Riboflavine- $\mathrm{H}_{2}+\mathrm{D}$

Riboflavine- $\mathrm{H}_{2}+\mathrm{O}_{2} \rightarrow$ Riboflavine

$+\mathrm{H}^{+}+\mathrm{O}_{2}^{-}$

$2^{e}$ phase:

Riboflavine- $\mathrm{H}_{2}+\mathrm{O}_{2} \rightarrow$ Riboflavine $+\mathrm{H}_{2} \mathrm{O}_{2}$ $\mathrm{O}_{2}^{-}+\mathrm{H}_{2} \mathrm{O}_{2} \rightarrow \mathrm{OH}^{-}+\mathrm{OH}^{-}+\mathrm{O}_{2}$

Riboflavine $+\mathrm{O}_{2}^{-}\left(\mathrm{ou} \mathrm{OH}^{-}\right)$

$\rightarrow$ Décomposition de la riboflavine

Dans le lait, l'oxygène excité peut être décomposé en eau oxygénée en présence de peroxyde-dismutase. Ces 2 composés (c'est-à-dire l'oxygène excité et l'eau oxygénée) peuvent en effet être mis en évidence dans le lactosérum après une exposition à la lumière. Sous l'effet d'un éclairement plus intense, il semble que l'oxygène excité ne participe plus à la photodestruction de la riboflavine (Toyosaki et al, 1988). II a été démontré que cette photodestruction est plus rapide dans des systèmes modèles comportant des protéines lactosériques ( $\alpha$-lactalbumine ou $\beta$ lactoglobuline) que dans une solution de riboflavine pure, ce qui semblerait indiquer une participation de ces protéines à la photolyse de la riboflavine dans le lait (Toyosaki et Mineshita, 1989). Dans ces systèmes modèles, les produits de réaction finaux semblent pourtant être les mêmes que dans le lait (Toyosaki et Mineshita, 1990). À l'aide d'une analyse par GC-MS, Parks et Allen (1977) ont mis en évidence le lumichrome comme principal produit de la photodécomposition de la ri- boflavine dans le lait maigre exposé à la lumière.

\section{La méthionine à l'origine du goût de lumière}

Le méthional (méthylmercaptopropionaldéhyde) ainsi que ses produits de décomposition (mercaptanes, sulfures et disulfures etc) sont les principaux responsables du goût de lumière perçu dans le lait et les produits laitiers exposés à la lumière. Ces substances sont elles-mêmes issues de la photodécomposition de la méthionine. Patton et Josephson (1953) ont observé un défaut (goût et odeur) de lumière plus intense et plus caractéristique dans le lait écrémé préalablement enrichi en méthionine et exposé à la lumière. Le méthional a également été mis en évidence par spectrométrie de masse dans le lait écrémé exposé à la lumière solaire (Allen et Parks, 1975). Patton (1954) a mesuré des concentrations atteignant $50 \mathrm{ppb}$ dans du lait entier. La riboflavine participe toujours à cette réaction (fig 12).

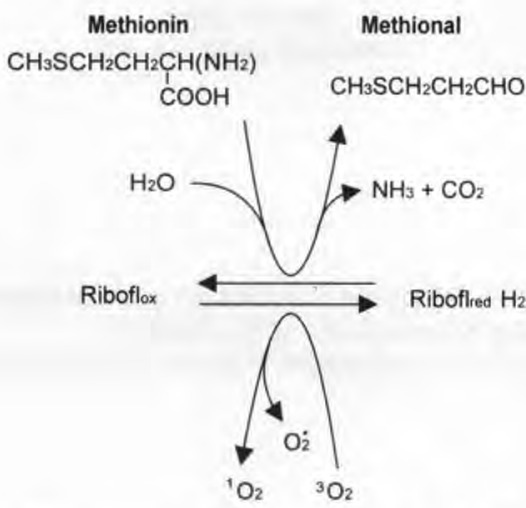

Fig 12. Formation de méthional sous l'action de la lumière en présence de riboflavine (Dimick, 1982, modifié).

Light-induced methional formation in the presence of riboflavin. 


\section{Oxydation des graisses}

Les réactions photocatalytiques dans lesquelles la riboflavine est impliquée comme photosensibilisateur sont des plus complexes. La figure 11 montre qu'il se forme, sous l'effet de la lumière, de l'oxygène activé singulet $\left({ }^{1} \mathrm{O}_{2}\right)$. Ce dernier réagit avec les acides gras insaturés et produit des peroxydes (ou peracides) (Aurand et al, 1977). Du point de vue de la formation des peroxydes, la photo-oxydation se distingue de l'auto-oxydation dans sa phase initiale. L'auto-oxydation est définie comme la réaction des doubles liaisons avec l'oxygène en l'absence de photons (Mörsel, 1990).

\section{INFLUENCE DES OXYDANTS ET DES ANTIOXYDANTS}

Le développement des défauts de flaveur du lait et des produits laitiers sous l'effet de la lumière peut être influencé par la présence de nombreux oxydants et antioxydants tels que l'oxygène dissous, la ri- boflavine, l'acide ascorbique, le $\beta$ carotène, le tocophérol, les acides gras insaturés, les métaux de transition $\mathrm{Cu}$ (II), les composés sulfhydryles et la peroxydedismutase. L'oxygène, contre lequel l'emballage n'offre pas toujours une barrière suffisante, représente, conjointement à la riboflavine, l'une des substances clés pour la formation du goût de lumière, comme déjà indiqué. En pratique, il suffit généralement de traces d'oxygène pour occasionner ce type de défaut de flaveur.

Aurand et al (1977) apportent une preuve de la synergie de ces divers agents et de la lumière. Ces auteurs ont en effet étudié l'influence de cette dernière sur la peroxydation des lipides du lait en se servant de "bloquants" ("quenchers") de l'oxygène singulet. Pour effectuer leurs mesures, ils ont utilisé le test à l'acide thiobarbiturique (TBA) qui a permis de doser le malonyldialdéhyde formé pendant l'oxydation des lipides. Ils ont constaté que la lumière, en l'absence d'oxygène, ne modifiait pas le résultat de ce test. Ils ont également démontré que même l'utilisation de peroxydedismutase restait sans effet (tableau XIV).

Tableau XIV. Effet d'inhibiteurs de l'oxygène singulet sur la peroxydation des lipides induite par la lumière (Aurand et al, 1977).

Inhibiting effect of singlet oxygen quenchers on light-induced lipid peroxidation.

Description de l'échantillon

Valeur mesurée avec le test au TBA $\left(A \times 10^{3}\right)$ au

\begin{tabular}{llll}
\hline Début & $3^{e} j$ & $5^{e} j$
\end{tabular}

\section{Lait cru (témoin)}

Lait cru + lumière

Lait cru + lumière sans oxygène

Lait cru + lumière + filtre

Lait cru (témoin)

Lait cru + lumière

Lait cru + POD $\left(10^{-8} \mathrm{~mol}^{-1} \mathrm{I}^{-1}\right)$

Lait cru + POD $\left(10^{-8} \mathrm{~mol}^{-1^{-1}}\right)+$ lumière

Lait cru + POD $\left(6 \times 10^{-8}\right.$ mol. I $\left.^{-1}\right)+$ lumière

$\begin{array}{ll}21 & \\ 34 & \\ 27 & \\ 18 & \\ & \\ 27 & \\ 40 & \\ 23 & \\ 48 & 5 \\ 47 & 5\end{array}$

$\begin{array}{lll}22 & 20 & 24 \\ 42 & 86 & 92 \\ 29 & 29 & 26 \\ 16 & 18 & 14 \\ & & \\ 28 & 28 & 28 \\ 50 & 62 & 97 \\ 26 & 26 & 32 \\ 58 & 65 & 80 \\ 62 & 69 & 73\end{array}$

$A=$ Extinction; $P O D=$ peroxyde-dismutase; $T B A=$ acide thiobarbiturique.

A: Extinction; POD: peroxide dismutase; TBA: thiobarbituric acid. 
Pour le yoghourt nature, les propres travaux des auteurs et de leurs collègues ont clairement indiqué que les effets protecteurs offerts par les divers matériaux testés ne sont pas les mêmes à l'égard de l'oxygène et à l'égard de la lumière (tableau XV). En raison vraisemblablement du pouvoir réducteur (potentiel rédox) relativement élevé qu'offre la flore vivante des yoghourts, il semble plus important d'assurer une protection efficace contre les effets de la lumière que contre ceux de l'oxygène. Ces derniers doivent néanmoins être contrés dans toute la mesure du possible en raison de la synergie de ces 2 effets, discutés en détail ci-avant. Comme protection contre la lumière, un matériau quasi opaque comme le polystyrène cartonné ou fortement coloré en brun-rouge (verre ou polystyrène pigmenté) sont idoines. Comme protection contre la diffusion de l'oxygène, le verre reste l'emballage de choix (Bosset et Flückiger, 1986).

\section{INFLUENCE DES TRAITEMENTS TECHNOLOGIQUES \\ SUR LA PHOTOSENSIBILITÉ DU LAIT ET DES PRODUITS LAITIERS}

L'utilisation d'un procédé de fabrication ou l'établissement d'une technologie à mode opératoire normalisé (Standard Operation Procedure $=$ SOP) doit également tenir compte de la photosensibilité spécifique du produit considéré et des conditions dans lesquelles il sera exposé à la lumière. Sa teneur notamment en composés réducteurs et en composés oxydants (système rédox) peut jouer un rôle non négligeable dans la formation de produits de photodécomposition, ce qui devrait donc être mis à profit pour accroître la photoprotection dudit produit.

Partant de la constatation souvent faite dans la pratique que tous les laits pasteurisés ne présentent pas la même sensibilité à la lumière, un essai a été entrepris visant à évaluer l'influence respective des étapes de fabrication, soit l'homogénéisation et le traitement thermique. À cette fin, le lait cru utilisé (rappel des normes : $<48 \mathrm{~h}$ après la traite et < 500000 germes mésophiles aérobies (= UFC) par $\mathrm{ml}$ ) a été homogénéisé respectivement à 60,120 et 180 bar et respectivement à 60,65 et $70^{\circ} \mathrm{C}$. En ce qui concerne le traitement thermique appliqué, ce lait a été pasteurisé respectivement à 75,82 et $89^{\circ} \mathrm{C}$ pendant $16 \mathrm{~s}$. Toutes ces opérations ont été effectuées à l'aide d'une installation pilote Stork avec un débit de $\mathbf{8 0}$ /h. Le lait ainsi obtenu a été mis dans des bouteilles de verre clair de 1 I remplies aux $3 / 4$ (250 $\mathrm{ml}$ d'air restant dans l'espace de

Tableau XV. Effets protecteurs de divers matériaux d'emballage testés avec le yoghourt nature (Bosset et Flückiger, 1986).

Protective effect of packaging materials tested with natural yoghurt.

$\begin{array}{llll}\text { Matériau d'emballage } \quad \text { Abrév } \quad \begin{array}{l}\text { Protection } \\ \text { contre la lumière }\end{array} & \begin{array}{l}\text { Protection } \\ \text { contre l'oxgène }\end{array} & \begin{array}{c}\text { Classement } \\ \text { parprotection } \\ \text { globale décroissante }\end{array}\end{array}$

\begin{tabular}{lllll} 
Verre teinté brun-rouge & V/B & Bonne & Optimale & 1 \\
Polystyrène cartonné & PS/C & Très bonne & Mauvaise & 2 \\
Polystyrène teinté brun-rouge & PS/B & Bonne & Moyenne & 3 \\
Verre incolore & V/I & Médiocre & Optimale & 4 \\
Polystyrène incolore & PS/I & Mauvaise & Moyenne & 5 \\
\hline
\end{tabular}


tête), puis stocké $20 \mathrm{~h}$ durant sous un éclairement de $750 \mathrm{~lx}$ de type blanc chaud (cf essai V, Rappel des principales conditions de travail adoptées précédemment par les auteurs).

\section{Pression et température d'homogénéisation}

Un accroissement de la pression d'homogénéisation de 60 à 180 bar correspond à une réduction de la taille des globules gras ainsi qu'à une légère dénaturation des protéines lactosériques. Les diverses variantes d'homogénéisation testées (pression et température) n'ont fait apparaître que peu de différence dans la photosensibilité du lait obtenu. Le facteur temps d'exposition est en revanche très important: après $12 \mathrm{~h}$ apparaît un défaut caractéristique de goût de lumière, de suif et d'oxydé (fig 13) tout particulièrement prononcé à 120 bar (pression d'homogénéisation moyenne).

L'influence de la température a été étudiée entre 60 et $70^{\circ} \mathrm{C}$ sur la base d'une homogénéisation à 2 étages ( $120 \mathrm{bar} / 30 \mathrm{bar}$ ) suivie d'une pasteurisation à $82^{\circ} \mathrm{C}$ pendant $16 \mathrm{~s}$. L'exposition de ces 3 variantes de lait a sensiblement conduit aux mêmes conclusions que précédemment, soit une altération marquée de la flaveur après $12 \mathrm{~h}$ d'exposition à la lumière. On n'observe aucune dépendance particulière de la température d'homogénéisation (fig 14), en raison probablement de l'effet ultérieur de la température de la pasteurisation.

\section{Température de pasteurisation}

En plus de l'effet de l'homogénéisation, celui du traitement thermique appliqué au lait (pasteurisation, traitement UHT etc) joue un rôle clé pour la photosensibilité du produit final.

\section{Pression d'homogénéisation}
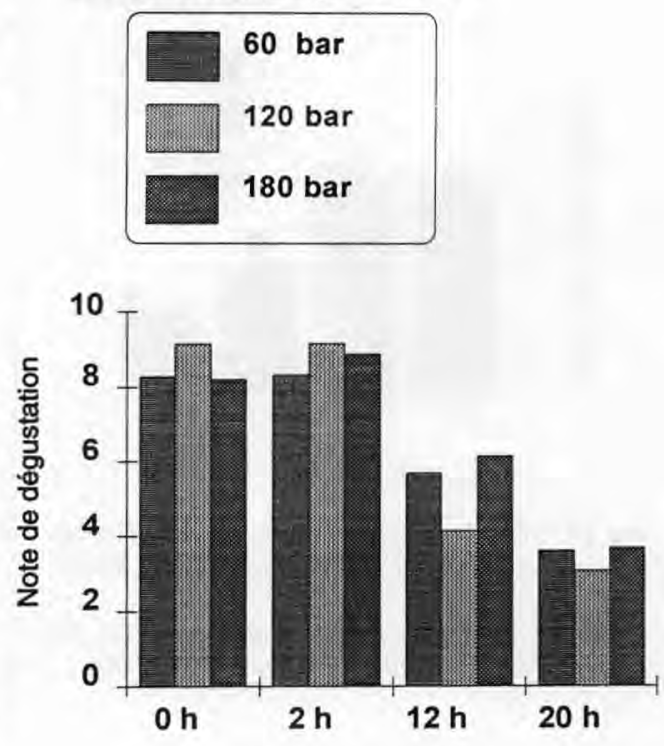

Exposition de la lumière

Fig 13. Effet de la pression d'homogénéisation sur la photosensibilité du lait (test sensoriel). Effect of homogenisation pressure on the sensitivity of milk (sensorial evaluation).

Les essais effectués entre 75 et $89^{\circ} \mathrm{C}$ (pasteurisation) ont conduit à une dénaturation croissante des protéines lactosériques ainsi qu'à une réduction massive du nombre de germes vivants. La figure 15 montre I'influence de la température de pasteurisation sur la photosensibilité du lait à l'aide d'un test sensoriel. En l'absence ou après une très courte durée $(<2 \mathrm{~h})$ d'exposition à la lumière, on constate que les notes de dégustation sont attribuées en raison inverse de l'importance du traitement thermique appliqué. Le lait considéré comme le meilleur est celui qui a été le moins chauffé $\left(75^{\circ} \mathrm{C}\right)$, la classification étant basée sur l'importance du goût de cuit (goût de brûlé). Pour des durées crois- 


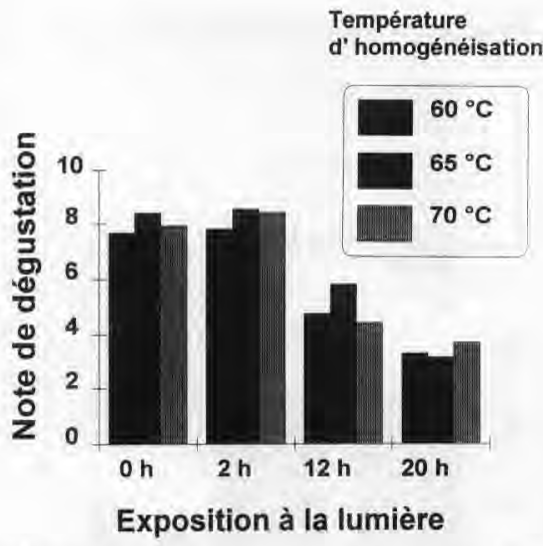

Fig 14. Effet de la température d'homogénéisation sur la photosensibilité du lait (test sensoriel).

Effect of homogenisation temperature on the photosensitivity of milk (sensorial evaluation).

\section{Température de pasteurisation:}

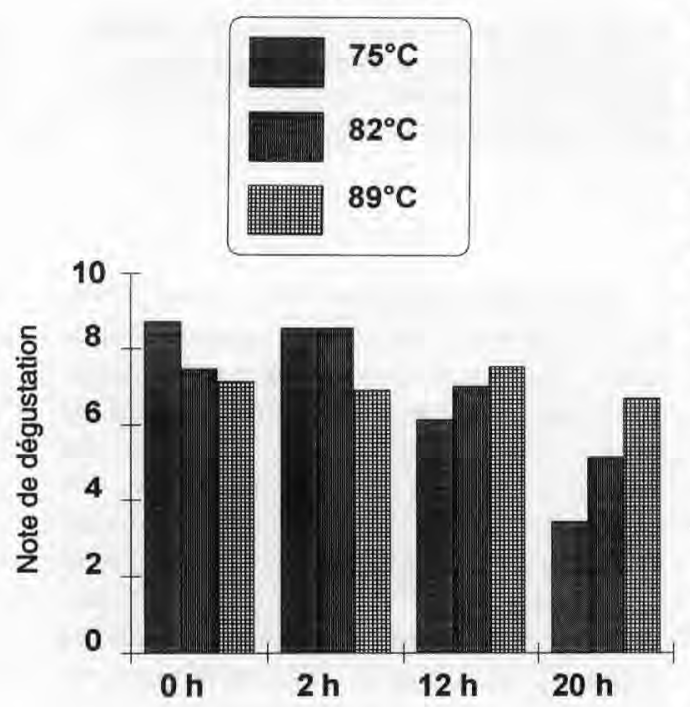

Exposition à la lumière

Fig 15. Effet de la température de pasteurisation sur la photosensibilité du lait (test sensoriel).

Effect of pasteurisation temperature on the photosensitivity of milk (sensorial evaluation). santes d'exposition à la lumière (> $12 \mathrm{~h}$ ), on constate en revanche une inversion de la classification de ces laits (critère de préférence), la meilleure note ayant alors été donnée au lait le plus fortement chauffé $\left(89^{\circ} \mathrm{C}\right)$. Seul ce lait est encore considéré comme apte à la consommation, tous les autres étant fortement dépréciés par leur goût de lumière, d'oxydé ou de suif. En conclusion, on constate un antagonisme des effets dus à une exposition à la lumière et de ceux dus au traitement thermique appliqué: les premiers engendrent un état oxydant (photo-oxydation), les seconds, un état réducteur ou réduit dû en particulier à la libération des groupes sulfhydryles à partir des groupes disulfures des acides aminés et des protéines lactosériques du lait (Eberhard, 1992, comm pers).

Les observations suivantes confirment le bien-fondé de cette explication. Dans un lait UHT conditionné dans un emballage de verre étanche à l'oxygène et entreposé. pendant $17 \mathrm{j}$ sous des éclairements de 600 et de $4000 \mathrm{~lx}$, la teneur initiale de $6,5 \mathrm{mg}$ d'oxygène dissous par litre de lait est tombée en dessous du seuil de détection. Aucun goût d'oxydé ou de lumière n'a néanmoins pu y être décelé. On peut en conclure que la faible teneur en oxygène initialement dosée dans ce lait a entièrement réagi avec les groupes sulfhydryles libérés par le traitement UHT (par ex. lors de l'oxydation de la cystéine en cystéine) ainsi qu'avec d'autres substances réductrices comme l'acide ascorbique. Dans des conditions semblables mais en présence cette fois d'un volume d'espace de tête correspondant à $8 \%$ du volume total du récipient ("excès» d'oxygène) est apparu un goût typique d'oxydé ou de lumière après 2 j d'éclairement sous 4000 Ix et après 10 j sous $600 \mathrm{~lx}$ (Schröder, 1983). En 1967 déjà, Ford a démontré, dans un lait pasteurisé directement exposé au soleil, que la destruction de l'acide ascorbique s'ac- 
compagne d'une réduction parallèle de la pression partielle d'oxygène $\left(\mathrm{pO}_{2}\right)$ de 187 à $13 \mathrm{~mm} \mathrm{Hg}$ en l'espace de $30 \mathrm{~min}$. Un rinçage (purge) rapide de ce lait à l'azote prévient en revanche toute perte en acide ascorbique. Ces diverses observations concordent encore avec d'autres à nouveau établies par Schröder (1983) et permettent de les expliquer : un lait traité par UHT et conditionné dans des bouteilles de verre, n'a nullement perdu de son acceptabilité après $24 \mathrm{j}$ sous $600 \mathrm{~lx}$, alors que $48 \mathrm{~h}$ ont suffi pour faire apparaître le défaut d'oxydé dans le même lait, si celui-ci est conditionné dans des bouteilles de polyéthylène perméables à l'oxygène. Biewendt et al (1991) ont aussi montré qu'aucune altération sensorielle significative de la flaveur ne se produisait dans un lait traité par UHT direct, s'il est conditionné dans des bouteilles de verre brun stockées pendant 12 semaines sous 500 ou 1600 Ix en lumière naturelle diffuse ou sous 500 Ix en lumière artificielle, comparativement à un lait de référence identique conservé à l'obscurité.

\section{CONCLUSIONS POUR LA PRATIQUE}

Le présent travail montre l'importance à accorder dans la pratique industrielle à la protection du lait et des produits laitiers à l'égard de la lumière. Cette demière est en effet la cause de nombreuses altérations tant de leur flaveur (apparition de défauts de saveur et d'odeur désignés en anglais par le terme général de "off-flavour") que de leurs propriétés nutritionnelles. Au nombre des substances clés participant aux indésirables - mais évitables - réactions de photodégradation du lait et des produits laitiers, on peut citer la riboflavine (vitamine $\mathrm{B}_{2}$ ) ainsi que l'oxygène dissous. Les principaux substrats de ces réactions sont les protéines et les acides aminés libres d'une part et les acides gras insaturés d'autre part.
Maints facteurs sont à même d'accroître ou de réduire la photosensibilité du lait et des produits laitiers en général. On peut schématiquement les classer en 2 grands groupes: les facteurs intrinsèques et les facteurs extrinsèques. Les facteurs intrinsèques sont généralement liés à la composition et à la constitution du produit lui-même. II est donc difficile en général de les influencer sans modifier la nature même du produit considéré. Parmi eux, on peut citer la composition générale ( $p a r$ ex : la teneur en composés oxydants ou réducteurs), la valeur du $\mathrm{pH}$, le potentiel d'oxydo-réduction, la teneur en oxygène dissous, la translucidité (ou son inverse : la turbidité) du produit ainsi que le traitement technologique appliqué (homogénéisation, échauffement avec la formation correspondante de groupes sulfhydryles réducteurs aux températures les plus élevées). Les facteurs extrinsèques ne font pas partie intégrante du produit, mais de son environnement. Ils peuvent donc généralement être choisis de façon optimale et adéquate. Parmi ces derniers, on peut mentionner:

- le spectre, l'intensité et la durée de la lumière incidente;

- la translucidité et la perméabilité à l'oxygène de l'emballage;

- la température d'entreposage du produit.

\section{Facteurs intrinsèques}

La photosensibilité spécifique du produit laitier à emballer doit être prise en compte.

Un lait cru ou pasteurisé à basse température $\left(72-75^{\circ} \mathrm{C}\right)$ est plus sensible à la lumière qu'un lait plus fortement chauffé, protégé par sa teneur accrue en composés réducteurs. La sensibilité à la lumière dépend donc du traitement thermique appliqué. L'action antioxydante des groupes sulfhydryles libérés par la chaleur y joue un rôle déterminant (Bürki, 1977; Bosset et 
al, 1983). Inversement, la technologie laitière actuelle en matière de pasteurisation tend à ménager au maximum le lait afin de lui conserver autant que possible ses propriétés naturelles. Un tel lait est donc plus exposé du point de vue de sa photodégradation. Ses exigences de photoprotection sont par conséquent plus grandes en dépit de sa relative brève durée de conservation (env 5 j). C'est donc à l'emballage qu'incombera, en principe, l'importante fonction de protection contre la lumière. Afin d'assurer une conservation correcte à un lait pasteurisé traité thermiquement de façon ménageante, il ne saurait donc être question de sacrifier sa fonction de photoprotection au seul profit d'exigences écologiques.

Contre les effets de l'oxygène - synergiques de ceux de la lumière -, le yoghourt est un peu mieux protégé par l'action réductrice de sa flore vivante. Cet avantage des yoghourts comparativement aux laits traités à basse température est néanmoins contrebalancé par d'autres facteurs aggravants tels que durée de stockage plus longue, rapport surface/volume du produit exposé plus défavorable, teneur accrue en acides aminés libres et tendance à utiliser des emballages toujours plus minces (coût et poids). Une telle tendance se traduit en effet par une augmentation correspondante de la translucidité et de la perméabilité à l'oxygène, surtout avec les emballages plastiques les plus courants (polystyrène). Si le yoghourt y paraît plus "naturel" et plus attractif, il y est en revanche beaucoup plus exposé aux effets néfastes de la lumière. La teneur en pigments et en composés fortement antioxydants de certaines sortes de yoghourt, surtout ceux au mocca (ou café) et au chocolat, leur confère une importante photoprotection naturelle dont ne disposent pas les yoghourts de type nature et fraise.

Le fromage est certainement moins exposé à la photodégradation en raison de sa structure plus compacte (faible profondeur de pénétration de la lumière), de sa teneur en oxygène dissous plus faible (teneur en matière sèche élevée et caractère réducteur de sa flore microbienne) ainsi que de sa teneur en riboflavine (hydrosoluble) réduite par l'égouttage du petit-lait. On tiendra compte pourtant de sa durée de stockage relativement longue, de sa géométrie d'exposition parfois peu judicieuse (à l'état râpé, en lamelles ou en tranches fines), de même que du peu de photoprotection qu'offre la feuille de plastique transparente qui entoure les fromages découpés préemballés.

Le beurre est particulièrement exposé à la photodégradation puisqu'il est très riche en acides gras (notamment insaturés), qu'il possède suffisamment de riboflavine et d'eau pour dissoudre l'oxygène nécessaire pour générer de l'oxygène excité. Trois autres facteurs contribuent encore à accroître le risque d'une photodégradation : une température de stockage basse (d'où une augmentation de la solubilité de l'oxygène), une durée de stockage très longue (plusieurs mois) ainsi qu'une profondeur de pénétration relativement grande de la lumière dans le milieu (structure moins photodiffusante que celle du fromage par exemple).

\section{Facteurs extrinsèques}

\section{Matériau d'emballage}

Des matériaux opaques ou très fortement photodiffusants constituent en principe des matériaux de choix pour l'emballage puisqu'ils limitent fortement la translucidité, c'est-à-dire la transmission de la lumière incidente. De tels matériaux présentent cependant le double inconvénient de ne pas laisser "visible" le contenu (d'où une diminution de son caractère attractif pour le 
consommateur) et de représenter souvent des coûts de production sensiblement plus élevés (par ex doublage par une feuille d'aluminium pour les laits UHT, bécher «К3" pour les yoghourts). Si une certaine transparence est souhaitée, on donnera alors la préférence à un emballage teinté ou pigmenté brun-rouge (couleur complémentaire du bleu-vert) afin de limiter autant que possible l'absorption de lumière par la riboflavine qui agit comme photosensibilisateur.

Pour choisir en définitive le matériau le plus adéquat, on tiendra compte encore d'autres éléments d'appréciation (Fink, 1990) tels que ses propriétés de transformation, ses propriétés mécaniques et fonctionnelles ainsi que la charge qu'il représente pour l'environnement (obtention, recyclage, récupération ou élimination) comme l'indique schématiquement la figure 1. À cette fin, il est nécessaire d'évaluer avec soin et rigueur et en connaissance de cause les véritables risques encourus par le produit en fonction également des conditions de distribution jusqu'au consommateur, sans surestimer toutefois lesdits besoins de photoprotection. Lorsque plusieurs facteurs, parfois opposés, entrent en ligne de compte, ce sont en général des tests pratiques en temps réel, ou éventuellement en accéléré, qui donnent les meilleurs résultats et les meilleures réponses quant à la protection minimale à garantir (Bosset et Flückiger, 1989). Les essais entrepris avec divers yoghourts ont clairement montré que les résultats obtenus avec le yoghourt nature ne sont pas directement transposables à d'autres sortes telles que fraise et surtout mocca et chocolat qui se sont révélées beaucoup moins sensibles à la lumière, donc moins exigeantes quant à leur photoprotection.

Au lieu de teinter un emballage en brunrouge, on peut aussi le munir d'une barrière à la lumière. Une telle solution a été adoptée en Suisse lors de l'introduction du lait pasteurisé en sachets souples réalisés avec un matériau composite incluant un film interne opaque (Eberhard et Gallmann, 1991).

\section{Source de lumière}

Pour le stockage, il est impératif de choisir si possible une source de lumière pauvre en composantes bleu-vert $(350-550 \mathrm{~nm})$ afin de limiter autant que possible toute émission dans le domaine spectral correspondant à la troisième bande d'absorption de la riboflavine ( $\lambda_{\max }$ à environ $444 \mathrm{~nm}$ ). Aussi choisira-t-on de préférence des tubes fluorescents d'un type "blanc chaud", à dominante jaune-rouge (par ex. Philips TL 58, Philips TL 82, Osram 36, Thorn NX) plutôt que ceux de type "blanc froid", à dominante bleu-vert (par ex Philips 33).

On veillera de plus à prévenir tout éclairement excessif - aussi inutile que dangereux du point de vue photolytique et photocatalytique - en limitant la puissance de la source lumineuse, en éloignant les produits de celle-ci (l'énergie incidente diminue avec le carré de la distance), en les empilant, en les disposant et les orientant de façon judicieuse et en utilisant toutes les "chicanes" optiques possibles, susceptibles d'atténuer l'énergie atteignant le lait et les produits laitiers (harasses, caissettes, paniers etc. facilitant d'ailleurs leur transport et leur manutention).

On limitera enfin la durée de l'exposition à la lumière au strict minimum nécessaire (stockage à l'obscurité, utilisation d'horloge/minuterie pour les vitrines et les présentoirs destinés à la vente) (Bosset et al, $1986 a, b)$.

\section{Température}

Quant à la température, elle devrait être maintenue aussi basse que possible pour 
limiter les énergies et les vitesses de photodécomposition. Cette directive correspond d'ailleurs à l'une des exigences de base de la conservation microbiologique du lait et des produits laitiers. Une telle condition améliore pourtant la solubilité de l'oxygène dans le produit à protéger des effets de la lumière. Dans la mesure du possible, on compensera ce facteur négatif en choisissant un emballage peu perméable à l'oxygène. On tiendra compte enfin d'une éventuelle élévation de la température due à la conversion de l'énergie lumineuse en énergie thermique par des emballages de teinte foncée. Cette situation peut se rencontrer par exemple lors de l'exposition de bouteilles de verre brun à la lumière solaire (Hendrickx et de Moor, 1962).

\section{REMERCIEMENTS}

Les auteurs tiennent à remercier leurs collègues de la maison Nestlé à Lausanne et La Tour-dePeilz, N Daget, C Desarzens, A Dieffenbacher et $E$ Tagliaferri, ainsi que leurs collègues de la FAM à Liebefeld-Berne, notamment, $P$ Eberhard, $H$ Eyer et $R$ Gauch de leur intérêt et de leur soutien actif (dosages, évaluations, mise à disposition de tableaux et de figures) lors des travaux qui sont à la base de cette synthèse bibliographique.

\section{REFERENCES}

Allen C, Parks OW (1975) Evidence for methional in skim milk exposed to sunlight. J Dairy Sci $58,1609-1611$

Allen C, Parks OW (1979) Photodegradation of riboflavin in milks exposed to fluorescent light. J Dairy Sci 62, 1377-1379

Andersen KP (1959) The influence of light on ascorbic acid destruction and oxidized flavours in milk. XV Int Dairy Congr 3, 17461753

Anonyme (1980) Vitamin-Compendium. Hoffmann-La Roche, Bâle 2 Aufi
Anonyme (sans année) Solar simulation for research and industry. Oriel, Stamford

Aurand LW, Boone NH, Giddings GG (1977) Superoxide and singlet oxygen in milk lipid peroxidation. J Dairy Sci 60, 363-369

Azzara C, Campbell LB (1992) Off-flavors of dairy products. In: Off-flavors in foods and beverages (Charalambous G, ed) Elsevier Sci Publ, London, 329-374

Bartholomew BP, Ogden LV (1990) Effect of emulsifiers and fortification methods on light stability of vitamin A in milk. J Dairy Sci 73 , 1485-1488

Bassette R (1976) Effects of light on concentrations of some volatile materials in milk. J Milk Food Technol 39, 10-12

Bates CJ, Liu D-S, Fuller NJ, Lucas A (1985) Susceptibility of riboflavin and vitamin $A$ in breast milk to photodegradation and its implications for the use of banked breast milk in infant feeding. Acta Paediatr Scand 74, 40-44

Bekbölet M (1990) Light effects on food. J Food Prot 53, 430-440

Berlage-Weinig L (1983) Untersuchungen zur sensorischen Qualität und zur Vitaminwertigkeit von UHT-Milch und pasteurisierter Milch. Dissertation Justus-Liebig-Universität Giessen 1-152

Biewendt H-G, Manasterny K, Moltzen B (1991) Untersuchung der Lichtschutzwirkung brauner Mehrwegglasflaschen bei direkt erhitzter H-Milch Kiel Milchwirt Forschungsber 43, 307-316

Bojkow E (1970) Lichtschutz und Milchverpakkung. I. Mitteilung: Allgemeine Grundlagen. Öst Milchwirt 25, 449-478

Bojkow E (1984) Praxisbezogene Beurteilung der Lichtschutzeigenschaften von Verpakkungen für Molkereiprodukte. Disch Molk Ztg 105, 1592-1598

Bosset JO, Daget N, Desarzens C, Dieffenbacher A, Flückiger $E$, Lavanchy $P$, Nick $B$, Pauchard JP, Tagliaferri E (1986a) The influence of light transmittance and gas permeability of various packing materials on the quality of whole natural yoghurt during storage. In: Food packaging and preservation. Theory and practice (Mathlouthi M, ed) Elsevier Appl Sci Publ, London, 235-270

Bosset JO, Desarzens C, Blanc B (1983) La photodégradation du lait et de quelques pro- 
duits laitiers. Partie II : Influence de certains facteurs chimiques et chimico-physiques sur l'altération de la seule couleur. Lebensm Wiss Technol 17, 248-253

Bosset JO, Eberhard P, Bütikofer U, Sieber R, Tagliaferri $E$ (1991) Evaluation de quelques critères d'altération du lait entier soumis à divers traitements thermiques et mécaniques ainsi qu'à diverses durées d'exposition à la lumière. Partie I : Étude de la vitamine C. Trav Chim Aliment Hyg 82, 433-456

Bosset JO, Flückiger $E$, Lavanchy $P$, Nick $B$, Pauchard JP, Daget N, Desarzens C, Dieffenbacher A,Tagliaferri E (1986b) Influence de la translucidité et de la perméabilité aux gaz de différents matériaux d'emballage sur la qualité du yoghourt entier nature en cours de stockage. Lebensm Wiss Technol 19, 104-106

Bosset JO, Flückiger E (1985) Guter Licht- und Gasschutz sind wichtig! Schweiz Milchztg 111,440

Bosset JO, Flückiger E (1986) Einfluss der Lichtund Gasdurchlässigkeit verschiedener Pakkungsarten auf die Qualitätserhaltung von $\mathrm{Na}$ turjoghurt. Dtsch Milchwirt 37, 908-914

Bosset JO, Flückiger E (1989) Die Verpackung als Mittel zur Qualitätserhaltung von Lebensmittein, dargestellt am Beispiel der Lichtschutzbedürftigkeit verschiedener Yoghurtsorten. Lebensm Wiss Technol 22, 292-300

Bosset JO, Gauch R (1988) Effet protecteur de l'emballage contre la photo-oxydation. I. Étude par GS-MS de quelques composés carbonylés et du méthional dans divers yoghourts en cours de stockage. Trav Chim Aliment Hyg 79, 165-174

Bradley RL (1980) Effect of light on alteration of nutritional value and flavor of milk: a review. $J$ Food Prot 43, 314-320

Bürki C (1977) Verhalten der Sulfhydril- und Disulfidgruppen in proteinhaltigen wässerigen Systemen, dargestellt am Beispiel der Milchproteine. Diss ETH Zürich Nr 5924

Burton H (1951) Ultra-violet irradiation of milk. Dairy Sci Abstr 13, 229-245

Causeret J, Hugot D, Goulas-Scholler C, Mocquot G (1961) Évolution de la teneur du lait stérilisé en riboflavine et en vitamine $A$ au cours d'une conservation de longue durée. Ann Technol Agric 10, 289-300
Chen AO, Tsai YS, Chiu WTF (1992) Off-flavors of tea. In: Off-flavors in foods and beverages (Charalambous G, ed) Elsevier Sci Publ, London, 375-410

Chilson WH, Martin WH, Parish DB (1949) The relationship of ascorbic acid to the development of oxidized flavor in market milk. J Dairy Sci36, 306-315

Daget N (1989) Effet protecteur de l'emballage contre la photo-oxydation. V. Étude sensorielle de divers yoghourts en cours de stockage. Trav Chim Aliment Hyg 80, 87-99

Deger D, Ashoor SH (1987) Light-induced changes in taste, appearance, odor and riboflavin content of cheese. J Dairy Sci 70 , 1371-1376

deMan JM (1978) Possibilities of prevention of light-induced quality loss of milk. Can Inst Food Sci Technol J 11,152-154

deMan JM (1980) Effect of fluorescent light exposure on the sensory quality of milk. Milchwissenschaft $35,725-726$

deMan JM (1981) Light-induced destruction of vitamin A in milk. J Dairy Sci 64, 2031-2032

de Moor $H$, Hendrickx H (1970) L'influence de la lumière sur le goût du yaourt. Rev Agric 23, 1647-1654

Desarzens C (1988) Effet protecteur de l'emballage contre la photo-oxydation. III. Étude du $\mathrm{pH}$ et de la couleur de divers yoghourts en cours de stockage. Trav Chim Aliment Hyg $79,378-391$

Desarzens C, Bosset JO, Blanc B (1983) La photodégradation du lait et de quelques produits laitiers. Partie I : Altérations de la couleur du goût et de la teneur en quelques vitamines. Lebensm Wiss Technol 17, 241-247

Dieffenbacher A, Lüthi B (1986) Die direkte kolorimetrische Bestimmung der Peroxidzahl (POZ) in Milchprodukten. Mitt Gebiete Lebensm Hyg 77, 544-553

Dieffenbacher A, Trisconi M J (1988) Effet protecteur de l'emballage contre la photo-oxydation. II. Étude de l'indice de peroxydes et de la période dinduction de l'oxydation de la graisse libre dans divers yoghourts en cours de stockage. Trav Chim Aliment Hyg 79, 371-377

Dimick PS (1973) Effect of fluorescent light on the flavor and selected nutrients of homogenized milk held in conventional containers. J Milk Food Technol 36, 383-387 
Dimick PS (1976) Effect of fluorescent light on amino acid composition of serum proteins from homogenized milk. J Dairy Sci 59, 305308

Dimick PS (1982) Photochemical effects on flavor and nutrients of fluid milk. Can Inst Food Sci Technol J 15, 247-256

Dimick PS, Kilara A (1983) Photooxidative changes in milk proteins and amino acids. Kiel Milchwirt Forschungsber 35, 289-299

Eberhard P, Gallmann PU (1991) Ungenügender Lichtschutz für Milch im Schlauchbeutel. Schweiz Milchztg 117 (26) 3

Emmons DB, Froehlich DA, Paquette GJ, Butler G, Beckett DC, Modler HW, Brackenridge P, Daniels G (1986a) Light transmission characteristics of wrapping materials and oxidation of butter by fluorescent light. J Dairy Sci 69 , 2248-2267

Emmons DB, Paquette GJ, Froehlich DA, Beckett DC, Modler HW, Butler G, Brackenridge P, Daniels G (1986b) Oxidation of butter by low intensities of fluorescent light in relation to retail stores. J Dairy Sci 69, 2437-2450

Fanelli AJ, Burlew JV, Gabriel MK (1985) Protection of milk packaged in high density polyethylene against photodegradation by fluorescent light. J Food Prot 48, 112-117

Fellman RL, Dimick PS, Hollender R (1991) Photooxidative stability of vitamin A fortified $2 \%$ lowfat milk and skim milk. J Food Prot 54, 113-116

Ferretti L, Lelli ME, Miuccio C, Ragni C (1970) Variazioni quantitative di alcune vitamine nel latte UHT durante la conservazione Quad Nutr $30,124-133$

Fink P (1990) Lebensmittelverpackung - Schutz und Präsentation des Gutes. Mitt Gebiete Lebensm Hyg 81, 10-22

Foley J, O'Donovan D, Cooney C (1971) Photocatalysed oxidation of butter. J Soc Dairy Technol 24, 38-45

Ford JE (1967) The influence of the dissolved oxygen in milk on the stability of some vitamins towards heating and during subsequent exposure to sunlight. J Dairy Sci 34,239 247

Ford JE, Schröder MJA, Bland MA, Blease KS, Scott KJ (1986) Keeping quality of milk in relation to the copper content and temperature of pasteurization. J Dairy Res 53, 391-406
Fukumoto J, Nakashima K (1975) Protection of riboflavin in liquid milk from destruction by light using colour filters. $J$ Jpn Soc Food Nutr 28, 257-261, cité d'après Dairy Sci Abstr 38, 791 (1976)

Funai V (1956) Studies on riboflavin. Report 3. Destruction of riboflavin in milk by sunlight. Shikoku Acta Med 9, 78-88

Gaylord AM, Warthesen JJ, Smith DE (1986) Influence of milk fat milk solids and light intensity on the light stability of vitamin A and riboflavin in lowat milk. J Dairy Sci 69, 2779-2784

Gilmore TM, Dimick PS (1979) Photochemical changes in major whey proteins of cow's milk. J Dairy Sci 62, 189-194

Hedrick TI, Glass L (1975) Chemical changes in milk during exposure to fluorescent light. J Milk Food Technol 38, 129-131

Hendrickx $H$, de Moor $H$ (1962) L'influence de la lumière sur le lait en bouteilles ordinaires et en bouteilles colorées. Rev Agric 15, 723-738

Herreid EO, Ruskin B, Clark G, Parks TB (1952) Ascorbic acid and riboflavin destruction and flavor development in milk exposed to the sun in amber, clear, paper and ruby bottles. J Dairy Sci 35, $772-778$

Holmes AD, Jones CP (1945), Effect of sunshine upon the ascorbic acid and riboflavin content of milk. J Nutr 29, 201-209

Hoppner K, Lampi B (1985) Effect of fluorescent light on the folacin content of homogenized milk held in conventional containers. Can Inst Food Sci Technol J 18, 266-267

Hoskin J C (1988) Effect of fluorescent light on flavor and riboflavin content of milk held in modified half-gallon containers. J Food Prot $51,19-23$

Hoskin JC (1989) Susceptibility of cultured buttermilk to light irradiation. Cult Dairy Prod $J$ 24 (1) $14-15$

Hoskin JC, Dimick PS (1979) Evaluation of fluorescent light on flavor and riboflavin content of milk held in gallon returnable containers. $J$ Food Prot 42, 105-109

Hugot D, Lhuissier M, Causeret J (1962) Effet protecteur des bouteilles de verre ambré contre les pertes de riboflavine et de vitamine A dues à l'exposition du lait stérilisé à la lumière. Ann Technol Agric 11, 145-151

Janda JM (1990) Effect of fluorescence light on certain milk - a review. Agric Rev 11, 94-96 
Jenq W, Bassette R, Crang RE (1988) Effects of light and copper ions on volatile aldehydes of milk and milk fractions. $J$ Dairy Sci 71, 23662372

Josephson DV, Burgwald LH, Stoltz RB (1946) The effect of route delivery on the flavor, riboflavin and ascorbic acid content of milk. J Dairy Sci 29, 273-284

Kamimura M, Kaneda $H$ (1992) Off-flavors in beer. In: Off-flavors in foods and beverages (Charalambous G, ed) Elsevier Sci Publ, London 433-472

Kanner JD, Fennema O (1987) Photooxidation of tryptophan in the presence of riboflavin. J Agric Food Chem 35, 71-76

Kiermeier $F$, Waiblinger W (1969) Einfluss des Lichtes, insbesondere von Leuchtstoffröhren auf Vitamin $C$ - und $B_{2}$-Gehalt von in Polyăthylen verpackter Milch. Z Lebensm Unters Forsch 141, 320-331

Kon SK, Thompson SY (1953) The effect of light on riboflavin in milk. XIII Int Dairy Congr 2 , 363-367

Kon SK, Watson MB (1936) The effect of light on the vitamin D of milk. Biochem J 30,2273 2290

Korycka-Dahl M, Richardson T (1979) Photogeneration of superoxide anion upon illumination of bovine milk serum proteins with fluorescent light in the presence of riboflavin. J Dairy Sci 62, 183-188

Kristoffersen T, Stüssi DB, Gould IA (1964) Consumer-packaged cheese. I, Flavor stability. J Dairy Sci 47, 496-501

Luby JM, Gray JI, Harte BR, Ryan TC (1986a) Photooxidation of cholesterol in butter. J Food Sci 51, 904-907

Luby JM, Gray JI, Harte BR (1986b) Effects of packaging and light source on the oxidation stability of cholesterol in butter. J Food Sci 51, 908-911

Maniere FY, Dimick PS (1976) Effect of fluorescent light on repartition of riboflavin in homogenized milk. J Dairy Sci 59, 2019-2023

Maujean A, Seguin N (1983) Contribution à l'étude des gouts de lumière dans les vins de Champagne. 4. Approches à une solution oenologique des moyens de prévention des goûts de lumière. Sci Alim 3, 603-613

Mohammad KS, Al-Talib NA, Al-Kashab LA (1990) Some water-soluble vitamins in diffe- rent types of milk, their stabilities towards light and oxygen. Egypt $J$ Dairy Sci 18, 37 . 44

Mörsel J-T (1990) Lipidperoxidation. 1. Mitt. Primärreaktionen. Nahrung 34, 3-12

Neumann M, Garcia NA (1992) Kinetics, mechanism of the light-induced deterioration of lemon oil. J Agric Food Chem 40, 957-960

Nordlund J (1984) On defects in milk induced by light. Finn J Dairy Sci 42 49-51

Ohba T, Akiyama H (1992) Off-flavors of sake. In: Off-flavors in foods and beverages (Charalambous G, ed) Elsevier Sci Publ, London, 473-483

Olsen JR, Ashoor SH (1987) An assessment of light-induced off-flavors in retail milk. J Dairy Sci $70,1362-1370$

Paik JJ, Kim H (1976) Riboflavin in milk and milk products and the destructive effect of sunlight. Korean J Nutr 9, 164-168, cité d'après Dairy Sci Abstr 39, 462 (1977)

Palanuk SL, Warthesen JJ, Smith DE (1988) Effect of agitation, sampling location and protective films on light-induced riboflavin loss in skim milk. J Food Sci 53, 436-438

Parks OW, Allen C (1977) Photodegradation of riboflavin to lumichrome in milk exposed to sunlight. J Dairy Sci 60, 1038-1041

Patton S (1954) The mechanism of sunlight flavor formation in milk with special reference to methionine and riboflavin. J Dairy Sci 37, 446-452

Patton S, Josephson DV (1953) Methionine origin of sunlight flavor in milk. Science 118, 211

Peterson WJ, Haig FM, Shaw AO (1944) Destruction of riboflavin in milk by sunlight. $J \mathrm{Am}$ Chem Soc 66, 662-663

Radema $L$ (1962) The influence of light on milk in refrigerated display counters. XVI Int Milchw Kongr A, 561-568

Renner E, Baier D (1971) Einfluss des Lichtes auf den Gehalt der Milch an Ascorbinsäure und ungesättigten Fettsäuren. Disch Molk Ztg 92, 541-543

Renner E, Renz-Schauen A, Drathen M (1988) Einfluss der Lichtintensität in Verkaufstheken auf die Qualität pasteurisierter Milch in unterschiedlichen Verpackungen. Disch Molk Ztg 103, 609-612 
Renner E, Renz-Schauen A, Drathen M, Jelen $S$ (1989) Einfluss der Lichtintensität auf die Qualität pasteurisierter Milch in klaren und gefärbten Glasflaschen. Disch Molk Ztg 110 , 1006-1008

Richardson T, Korycka-Dahl M (1983) Lipid oxidation. In: Developments in dainy chemistry2 (Fox PF, ed) Applied Sci Publ, London, 241-363

Sander BD, Smith DE, Addis PB, Park SW (1989) Effects of prolonged and adverse storage conditions on levels of cholesterol oxidation products in dairy products. $J$ Food $\mathrm{Sci}$ 54, 874-879

Sattar A, deMan JM (1973) Effect of packaging material on light induced quality deterioration of milk. Can Inst Food Sci Technol J 6, 170174

Sattar A, deMan JM (1975) Photoxidation of milk and milk products. A review. CRC Crit Rev Food Sci Nutr 7, 13:37

Sattar A, deMan JM, Alexander JC (1977a) Wavelength effect of light-induced decomposition of vitamin $A$ and $\beta$-carotene in solution and milk fat. Can Inst Food Sci Technol J 10, 56-60

Sattar A, deMan JM, Alexander JC (1977b) Light-induced degradation of vitamins. I. Kinetic studies on riboflavin decomposition in solution. Can Inst Food Sci Technol J 10, 61-64

Sattar A, deMan JM, Alexander JC (1977c) Lightinduced degradation of vitamins. II. Kinetic studies on ascorbic acid decomposition in solution. Can Inst Food Sci Technol J 10, 65-68

Sattar A, Durrani MJ, Khan RN, Hussain BH (1989) Effect of packaging materials and fluorescent light on HTST-pasteurized orange drink. $Z$ Lebensm Unters Forsch 188 , 430-433

Schröder MJA (1983) Light and copper catalysed oxidized flavours in stored milk. $J$ Soc Dairy Technol 36, 8-12

Schröder MJA, Scott KJ, Bland MA, Bishop DR (1985) Flavour and vitamin stability in pasteurized milk in polyethylene-coated cartons and in polyethylene bottles. J SoC Dairy Technol 38, 48-52

Shipe WF, Bassette R, Deane DD, Dunkley WL, Hammond EG, Harper WJ, Kleyn DH, Morgan ME, Nelson JH, Scanlan RA (1978) Off flavors of milk: nomenclature standards and bibliography. J Dairy Sci61, 855-869
Sikka P, Narayan R, Atheya UK (1990) Effect of light and sterilization on milk riboflavin in cows and buffaloes. Indian J Dairy Sci 43, 598-600, cité d'après Dairy Sci Abstr 53, 887 (1991)

Singh RP, Heldman DR, Kirk JR (1975) Kinetic analysis of light-induced riboflavin loss in whole milk. J Food Sci 40, 164-167

Singleton JA, Aurand LW, Lancaster FW (1963) Sunlight flavor in milk. I. A study of components involved in the flavor development. J Dairy Sci 46, 1050-1053

Sinha SP (1963) The effect of fluorescent light on the vitamin $A$ and $B$-carotene content of milk. Int $J$ Vitam Res 33, 262-268

Somogyi JC, Ott E (1962) Die Wirkung des Lichtes auf den Vitamingehalt der Milch. Int $Z$ Vitaminforsch 32, 493-498

Stamberg OE, Theophilus DR (1945) Photolysis of riboflavin in milk. J Dairy Sci $28,269-275$

Stull JW (1953) The effect of light on activated flavor development and on the constituents of milk and its products: a review. J Dairy Sci 36, 1153-1164

Tagliaferri E (1989) Effet protecteur de l'emballage contre la photo-oxydation. IV. Étude de la stabilité des vitamines $A$ et $B_{2}$ dans divers yoghourts en cours de stockage. Trav Chim Aliment Hyg 80, 77-86

Tagliaferri E, Bosset JO, Bütikofer U, Eberhard $P$, Sieber R (1992a) Untersuchung einiger Kriterien zum Nachweis von Veränderungen der Vollmilch nach thermischen und mechanischen Behandlungen sowie nach verschieden langen Belichtungszeiten. II. Bestimmung des Vitamins $B_{1}$ mit Hilfe einer neuentwickelten RP-HPLC-Methode. Mitt Gebiete Lebensm Hyg 83, 435-452

Tagliaferri E, Sieber R, Bütikofer U, Eberhard P, Bosset JO (1992b) Untersuchung einiger Kriterien zum Nachweis von Veränderungen der Vollmilch nach thermischen und mechanischen Behandlungen sowie nach verschieden langen Belichtungszeiten. III. Bestimmung des Vitamins $B_{2}$ mit Hilfe einer neuentwickelten RP-HPLC-Methode. Mitt Gebiete Lebensm Hyg 83, 467-491

Toba T, Adachi S, Arai I (1980) Sunlight and sodium hypochlorite-induced color changes in milk. J Dairy Sci 63, 1796-1801

Toyosaki T, Mineshita T (1989) Mechanism of milk riboflavin photolysis in model systems. Milchwissenschaft 44, 292-294 
Toyosaki T, Mineshita T (1990) Mechanism of riboflavin photolysis studied by its decomposition products in model systems. Milchwissenschaft 45, 80-82

Toyosaki T, Yamamoto A, Mineshita T (1984) The photolysis mechanism of riboflavin in milk serum: the correlation between the superoxide and riboflavin decomposition. Agric Biol Chem 48, 2919-2922

Toyosaki T, Yamamoto A, Mineshita T (1987) Effects of water content and light intensity on riboflavin photodegradation in dairy products. Milchwissenschaft 42, 364-367

Toyosaki T, Yamamoto A, Mineshita T (1988) Kinetics of photolysis of milk riboflavin. Milchwissenschaft 43, 143-146

van der Mijll Dekker LP, Engel C (1952) The vi$\operatorname{tamin} A, B_{1}, B_{2}$ and $C$ contents of bottled sterilized milk during storage under various conditions. Neth Milk Dairy J 6, 104-108

van Dort HM, van der Linde LM, de Rijke D (1984) Identification and synthesis of new odor compounds from photolysis of thiamin. J Agric Food Chem 32, 454-457

Williams RR, Cheldelin VH (1942) Destruction of riboflavin by light. Science $96,22-23$

Wodsak W (1960) Die Haltbarkeit der Vitamine der Milch beim Pasteurisieren, Sterilisieren und bei der Herstellung von Kondensmilch. Nahrung 4, 209-224

Zahar M, Smith DE, Warthesen JJ (1986) Effect of carrier type and amount on vitamin A light degradation in fortified low-fat and skim milks. J Dairy Sci 69, 2038-2044

Zahar M, Smith DE, Warthesen JJ (1992) Effect of $\beta$-carotene on vitamin A light stability in fortified milk. Int Dairy J 2, 363-371

Zhang D, Mahoney AW (1990) Effect of iron fortification on quality of Cheddar cheese. 2. Effects of aging and fluorescent light on pilot scale cheeses.J Dairy Sci 73, 2252-2258

Ziegler JA (1944) Photochemical destruction of vitamin $B_{2}$ in milk. J Am Chem Soc 66, 10391044 